\title{
Multiple Endocrine Neoplasia Type 1 and the Pancreas: Diagnosis and Treatment of Functioning and Non-Functioning Pancreatic and Duodenal Neuroendocrine Neoplasia within the MEN1 Syndrome - An International Consensus Statement
}

\author{
Bruno Niederle $^{a} \quad$ Andreas Selberherr ${ }^{a}$ Detlef K. Bartsch ${ }^{b}$ Maria L. Brandic \\ Gerard M. Doherty ${ }^{d}$ Massimo Falconi ${ }^{e}$ Pierre Goudet $^{f}$
} Thorvardur R. Halfdanarson $^{g}$ Tetsuhide Ito ${ }^{h}$ Robert T. Jensen ${ }^{i}$ Alberto Larghi ${ }^{j}$ Lingaku Lee $^{\mathrm{i}}$ Kjell Öberg $^{\mathrm{k}}$ Marianne Pavel $^{\mathrm{l}}$ Aurel Perren $^{\mathrm{m}}$ Samira M. Sadowski ${ }^{n}$ Francesco Tonellio $^{\circ}$ Frédéric Triponez $^{p} \quad$ Gerlof D. Valk $^{q}$ Dermot O'Tooler ${ }^{r}$ David Scott-Coombes ${ }^{s}$ Rajesh V. Thakker ${ }^{t}$ Geoffrey B. Thompson " Giorgio Tregliav Bertram Wiedenmannw

aDepartment of Surgery, Medical University of Vienna, Vienna, Austria; ${ }^{b}$ Department of Visceral, Thoracic and Vascular Surgery, Philipps University Marburg, Marburg, Germany; 'Firmo Lab, Fondazione F.I.R.M.O. and University Florence, Florence, Italy; ${ }^{d}$ Department of Surgery, Brigham and Women's Hospital, Harvard Medical School, Boston, MA, USA; ePancreatic Surgery, San Raffaele Scientific Institute, "Vita-Salute" University, Milan, Italy; fService de Chirurgie Viscérale et Endocrinienne, Centre Hospitalier Universitaire François Mitterand, Dijon, France; gDepartment of Medical Oncology, Mayo Clinic Cancer Center, Rochester, MN, USA; hNeuroendocrine Tumor Centre, Fukuoka Sanno Hospital and Department of Gastroenterology, Graduate School of Medical Sciences, International University of Health and Welfare, Sawara-ku, Fukuoka, Japan; 'National Institute of Diabetes and Digestive and Kidney Diseases, National Institutes of Health, Bethesda, MD, USA; 'Digestive Endoscopy Unit, Fondazione Policlinico A. Gemelli IRCCS and Center for Endoscopic Research, Therapeutics and Training, Catholic University,

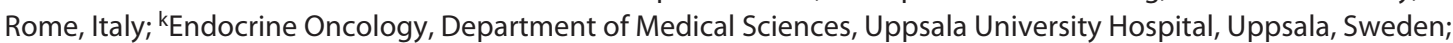
'Endocrinology and Diabetology, Department of Medicine 1, University Clinic of Erlangen, Erlangen, Germany; mInstitute of Pathology, University of Bern, Bern, Switzerland; ${ }^{n}$ Surgical Oncology Program, National Cancer Institute, National Institutes of Health, Bethesda, MD, USA; ${ }^{\circ}$ Department of Surgery and Translational Medicine,

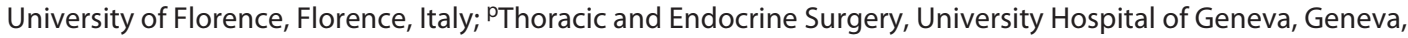
Switzerland; aDepartment of Endocrine Oncology, University Medical Center Utrecht, Utrecht, The Netherlands; 'Department of Clinical Medicine, St. James's Hospital and St Vincent's University Hospital and Trinity College, Dublin, Ireland; 's Department of Endocrine Surgery, University Hospital of Wales, Cardiff, UK; ${ }^{\mathrm{t} A c a d e m i c}$ Endocrine Unit, Oxford Centre for Diabetes, Endocrinology and Metabolism, Churchill Hospital, University of Oxford, Oxford, UK; " Section of Endocrine Surgery, Department of Gastroenterologic and General Surgery, Mayo Clinic, Rochester, MN, USA; VImaging Institute of Southern Switzerland, Ente Ospedaliero Cantonale, Bellinzona, Switzerland; wDepartment of Gastroenterology and Hepatology, Campus Virchow-Klinikum and Campus Charité Mitte, Charité Universitätsmedizin Berlin, Berlin, Germany 


\section{Keywords}

Multiple endocrine neoplasia type 1 . Neuroendocrine pancreatic tumors · Diagnosis - Treatment · Consensus statement

\section{Abstract}

The better understanding of the biological behavior of multiple endocrine neoplasia type 1 (MEN1) organ manifestations and the increase in clinical experience warrant a revision of previously published guidelines. Duodenopancreatic neuroendocrine neoplasias (DP-NENs) are still the second most common manifestation in MEN1 and, besides NENs of the thymus, remain a leading cause of death. DP-NENs are thus of main interest in the effort to reevaluate recommendations for their diagnosis and treatment. Especially over the last 2 years, more clinical experience has documented the follow-up of treated and untreated (natural-course) DPNENs. It was the aim of the international consortium of experts in endocrinology, genetics, radiology, surgery, gastroenterology, and oncology to systematically review the literature and to present a consensus statement based on the highest levels of evidence. Reviewing the literature published over the past decade, the focus was on the diagnosis of F- and NF-DP-NENs within the MEN1 syndrome in an effort to further standardize and improve treatment and follow-up, as well as to establish a "logbook" for the diagnosis and treatment of DP-NENs. This shall help further reduce complications and improve long-term treatment results in these rare tumors. The following international consensus statement builds upon the previously published guidelines of 2001 and 2012 and attempts to supplement the recommendations issued by various national and international societies.

(c) 2020 S. Karger AG, Basel

\section{Introduction}

Multiple endocrine neoplasia type 1 (MEN1; Online Mendelian Inheritance in Man \#131100) is a rare autosomal dominant and hereditary endocrine tumor syndrome caused by mutation of the MEN1 gene, a tumor suppressor gene on the long arm of chromosome 11 (11q13) that encodes the protein menin [1]. Menin in turn has multiple roles in cell division and proliferation, transcriptional regulation, and genome stability $[2,3]$. MEN1 shows a high degree of penetrance and may be diagnosed by clinical, familial, or genetic characteristics [4-8].

\section{Minimal Consensus Statement on the Definition of MEN1}

Clinical: A patient shows 2 or more MEN1-associated endocrine tumors (i.e., parathyroid adenoma, enteropancreatic tumor, and pituitary adenoma). Familial: A patient shows 1 MEN1-associated tumor and has a first-degree relative with MEN1. Genetic: A patient with one of the various MEN1 mutations does not show clinical (or biochemical) manifestations of MEN1 (asymptomatic gene carrier).

Apart from primary hyperparathyroidism (documented up to $100 \%$ ), duodenopancreatic neuroendocrine neoplasias (DP-NENs) are the second most common manifestation in MEN1 (30-90\%). They are, besides neuroendocrine tumors of the thymus, still the leading cause of death. Other features of MEN1 syndrome are tumors in the anterior pituitary (30-40\%) and the adrenal glands (in approximately 20-40\%). Less frequently, MEN1-associated NENs are diagnosed in the stomach, thymus, lung, bronchopulmonary tract (3-10\% of cases), and more recently in the female breast (around 7\%) [9].

\section{Minimal Consensus Statement}

Patients with MEN1 may develop F-NENs and NF-NENs of the duodenum and pancreas. F-NENs produce and secrete elevated levels of a specific gastrointestinal (GI) hormone (i.e., gastrin or insulin), resulting in clinical syndromes due to hormone excess. F-NENs are defined on the basis of clinical symptoms due to inappropriate hormone secretion rather than immunohistochemical findings. NF-DPNENs (inactive, clinically silent, and nonsyndromic) do not secrete the typical GI hormones and therefore cause no endocrine syndromes (asymptomatic DPNENs).

It was the aim of the international consortium of experts to systematically review the literature listed in PubMed, MEDLINE, and Embase (time period: 2000 to June 2020, and key publications prior to 2000) and to present a consensus statement based on the best scientific evidence available. The following consensus statement confirms or modifies former recommendations published previously for the diagnosis and treatment of MEN1 $[4,8]$, while attempting to supplement the recommendations issued by various national and international societies $[7,10-14]$. 
In terms of modern evidence-based medicine requirements, the available levels of evidence (LEs) for the diagnosis of DP-NENs within MEN1 and the clinical and therapeutic consequences are altogether low. There is currently a lack of evidence from controlled clinical trials to evaluate the best methods of diagnosis, treatment, and follow-up for DP-NENs. Based on the rarity of the disease, they will not become available in the near future.

The current recommendations concerning the necessity and value of diagnostic and therapeutic procedures are formulated on the basis of nonrandomized, nonprospective investigations and very often "case-control studies" (LE: III to IV; grade of recommendation [GR]: B/C). Methodological quality was assessed using the Oxford Center for Evidence-Based Medicine LEs and GRs (March 2009; see online suppl. Addendum 2; for all online suppl. material, see www.karger.com/doi/10.1159/000511791).

The Delphi method was applied and a questionnaire circulated among all authors in order to harmonize controversial topics. The preliminary draft of the manuscript was then prepared and sent to the external reviewers. The external reviewers of all specialties - endocrinology, genetics, radiology, surgery, gastroenterology, and oncology, and the representatives of the European Neuroendocrine Tumor Society (ENETS) and the European Society of Endocrine Surgeons (ESES) - submitted their expert opinions twice. Their recommendations and comments were included in the final manuscript.

While the current paper as a printed "short" version summarizes the further development of the former guidelines as minimal consensus statements, the "Supplement" as a long online version reviews the available English literature in more detail, including additional background information concerning DP disease within MEN1, presents expert advice on the diagnosis and management of DP-NENs and technical details of surgery, and documents the discussion of controversies.

\section{Epidemiology - Diagnosis - Indications for Treatment}

Epidemiology, Penetrance, Incidence, and Frequency

The estimated prevalence of MEN1 is 1 to $10 / 100,000$. The MEN1 genetic test facilitates the specific diagnosis of MEN1 and the early identification of asymptomatic carriers $[3,15]$. In most but not all patients, MEN1 presents clinically after the age of 21 years [16]. The clinical penetrance of the disease is nearly $100 \%$ by the age of $50[17$, $18]$.

Multiple Endocrine Neoplasia Type 1 and the Pancreas
The current guidelines [8] recommend genetic testing starting at the age of 5 years for MEN1 and annual biochemical (and imaging) screening in affected individuals. The aim of biochemical and imaging screening is to early detect organ manifestations with malignant behavior (e.g., DP-NEN or NEN in the thymus), to prevent, if malignant, their local and distant spread, to reduce the morbidity and mortality associated with endocrine syndromes, and, as a result of all, to preserve the quality of life. The techniques applied should be effective with regard to diagnostic yield documenting clinically relevant manifestations.

Genetic testing is recommended in all patients with clinical suspicion of MEN1 to confirm the diagnosis and in all first-degree relatives of MEN1 gene carriers [4, 19, 20]. There is an ongoing discussion whether genetic and biochemical testing as well as radiological imaging should be postponed until the second decade of life [21, 22]. Arguments for shifting genetic and biochemical examinations to the age of 16 and for prolonging the screening and follow-up intervals are that the majority of clinical manifestations start around that age [22]. There is no role for prophylactic medical treatment or surgery in asymptomatic individuals. With regard to psychological burden, distress on the part of positively screened but clinically asymptomatic individuals and their families, and cost-effectiveness, genetic, and routine screening as well as follow-up may be postponed until the age of 16 but has to be applied at the least when any clinical symptom becomes manifest, regardless of age [22].

Furthermore, it is discussed whether biochemical follow-up and radiological imaging should be extended if no clinically relevant organ manifestations were detected at the initial screening visit and in the family, since rapid progression of organ manifestations is rarely observed $[23,24]$. This more restricted screening strategy prohibits unnecessary examinations without missing serious manifestations [25].

DP-NENs are associated with an early age of onset (LE: 4) and are diagnosed at an early stage due to timely onset of periodic screening [18, 26-31]. The prevalence of DPNENs in MEN1 increases with age [8, 15, 16, 32-43]. Based on improved imaging techniques and regular screening, it becomes evident that the incidence of DPNENs is above $90 \%$ until the age of 70 years [44].

Earlier studies have suggested that most DP-NENs are functioning. NF-DP-NENs were infrequently reported in earlier studies and likely went undetected in many cases. More recent studies have suggested that NF-NENs are the most commonly encountered NENs in patients with

Neuroendocrinology 2021;111:609-630 611 
MEN1, followed by F-NENs such as gastrinomas and insulinomas (LE: 3b, GR: B) [27, 39, 45-50].

DP-NENs are equally prevalent among men and women [8], with the exception of a higher prevalence of gastrinomas in men [51]. However, gender-adapted diagnostic and therapeutic approaches cannot be recommended [52].

Minimal Consensus Statement on the Epidemiology, Penetrance, Incidence, and Frequency of

F-DP-NENs and NF-DP-NENs

The diagnosis of MEN1 should be considered for any patient with either a family history of endocrine tumors of the pancreas, pituitary, or parathyroid gland, or a family history of another endocrinopathy. Suspicion for MEN1 should be raised in patients who are diagnosed with a typical MEN1 manifestation at a young age ( $<30$ years), those with multiple DP-NENs, or DP-NENs associated with hypercalcemia or another endocrinopathy at any age. The clinical penetrance of the disease is nearly $100 \%$ by the age of 50 years. In order to reduce the morbidity and mortality associated with DP-NENs, biochemical and radiological screening may be postponed at least until the age of 16 years but must be applied at the least when clinical symptoms become manifest, regardless of age (LE: 4). Routine biochemical and imaging screening intervals can be extended from 1 to $2-3$ years in asymptomatic patients.

\section{Diagnosis and Follow-Up}

\section{Biochemical Diagnosis}

Following the current guidelines $[4,8]$, the application of a series of biochemical tests is recommended even in all asymptomatic MEN1 mutation carriers starting between the age of 10 years (insulinoma [fasting glucose, insulin]) and 20 years (gastrinoma [fasting gastrin levels]), or earlier adapted on the occurrence of clinical symptoms (LE: 3 ). In all newly diagnosed MEN1 patients, biochemical screening for DP-NENs aims to primarily assess the presence of F-DP-NENs mainly in patients with various clinical symptoms (LE: 3 ) [4, 8, 19, 53-56]. Biochemical tests and follow-up examinations are determined by local resources and clinicians' expertise and are a life-long program that respects patients' preferences $[57,58]$. There exist controversies regarding the value of several biochemical diagnostic tests in terms of sensitiv- ity and specificity (LE: 2b) [53]. Up to now, data prospectively acquired in randomized trials are lacking. In particular, the diagnostic accuracy of general neuroendocrine markers - chromogranin A (CgA), pancreatic polypeptide (PP), and glucagon - for the detection of DPNENs is low, especially in diagnosing NF-DP-NENs.

\section{F-DP-NENs}

The diagnosis of gastrinoma with Zollinger-Ellison syndrome (ZES) is suspected and unequivocally established if fasting serum gastrin (FSG) is $>10 \times$ normal with $\mathrm{pH}<2$. After identifying elevated FSG, an assessment of gastric $\mathrm{pH}$ is required at the time of repeat FSG determination to make sure the increased FSG is inappropriate $[59,59-61]$. Gastric fluid $\mathrm{pH}$ assessment is being increasingly carried out at the time of endoscopy [62] rather than using the older methods with nasogastric tubes.

The diagnosis of ZES has become more difficult [5961, 63-66] because of the increasing unreliability of commercial gastrin assays $[67,68]$, the lack of availability of secretin used to perform secretin provocative tests [69, 70], and the widespread use of proton pump inhibitors (PPIs), which cause rapid development of fasting hypergastrinemia in most non-ZES patients [59, 61, 64]. Unfortunately, elevated FSG can give a false-positive suggestion of ZES, as it may be elevated in patients with physiological hypergastrinemia (due to hypo-/achlorhydria secondary to any cause, such as atrophic gastritis, pernicious anemia, and PPIs) [59-61, 71, 72]. Furthermore, antral G-cell hyperfunction has been reported in MEN1, which can false-positively elevate FSG levels. Therefore, patients are recommended to be referred to an expert center to establish the diagnosis $[55,59,60]$.

For a long time, the secretin test, rarely available now and therefore infrequently applied, was recommended routinely [59-61, 71-75] as an important confirmatory tool to establish ZES in patients with FSG elevated $<10$ fold and gastric $\mathrm{pH}>2$. This is because a number of other conditions (antral G-cell hyperfunction, $H$. pylori infection, etc.) can be associated with hyperchlorhydria/hypergastrinemia in this range and the secretin test will distinguish them [59-61, 73, 74]. Numerous studies have demonstrated that the test is highly sensitive and specific for ZES under the proper conditions (acidic $\mathrm{pH}$, preferably pH <2) $[69,73,74]$.

Clinically suspected insulinoma is usually screened by blood glucose levels and fasting insulin, and thereafter, when definitively suspected, a formal assessment with 72-h fast with insulin, glucose, proinsulin, C-peptide, and excluding the presence of oral hypoglycemic agents $[10$, 
$55,71,76]$. In the case of glucagonomas, the diagnosis requires the demonstration of an elevated plasma glucagon level with evidence of glucagon hypersecretion clinically (diabetes; necrolytic migratory erythema; normochromic, normocytic anemia; etc.) $[55,71,77]$.

Vasoactive intestinal peptide-secreting tumors (VIPomas) demonstrate elevated plasma levels of vasoactive intestinal peptide (VIP). They cause a specific syndrome, watery diarrhea-hypokalemia-achlorhydria syndrome. The massive amounts of VIP cause profound and chronic (secretory) watery diarrhea, which characteristically exceeds $800 \mathrm{~mL} /$ day (pancreatic cholera syndrome) [55, $71,77,78]$.

\section{NF-DP-NENs}

The majority of NF-DP-NENs secrete different regulated secretory proteins not causing a functional syndrome. CgA and PP are frequently secreted, and glucagon, neuron-specific enolase, human chorionic gonadotropin subunits, calcitonin, and neurotensin are infrequently secreted [71]. These neuroendocrine markers may serve to early suspect NF-DP-NENs $[4,8]$.

There exist controversies regarding the value of several biochemical diagnostic tests in terms of sensitivity and specificity (LE: 2b) [53]. In particular, the diagnostic accuracy of general neuroendocrine markers (CgA, PP, and glucagon) for the detection of DP-NENs is low, especially in diagnosing NF-DP-NENs.

\section{Minimal Consensus Statement on the Biochemical Diagnosis of DP-NENs}

If biochemical screening is applied, it should be aimed at assessing the presence of both F- and NF-DPNENs. Biochemical screening for F-DP-NENs should imply fasting GI hormone profiles, including at least insulin with associated glucose levels and gastrin (LE: 3). In suspected insulinomas (low fasting glucose with elevated insulin), a 72-h fasting test should be performed under supervision, measuring and correlating glucose, insulin (proinsulin), and C-peptide. Drug screens for sulfonylureas should be checked at the end of the fast. In suspected gastrinomas (suspicious screening results: elevated FSG), FSG should be assessed in combination with gastric acid $\mathrm{pH}$. The diagnosis of ZES is unequivocally established if FSG is $>10$ $\times$ normal with $\mathrm{pH}<2$. Caution is warranted in patients with PPIs and atrophic (type A) gastritis - both are common and can falsely elevate FSG levels, leading to suspect gastrinoma. The secretin test is recommended

Multiple Endocrine Neoplasia Type 1 and the Pancreas to confirm ZES in patients with elevated FSG. However, secretin is not available in most countries. Glucagonomas should be suspected by history and diagnosed by elevated plasma glucagon levels with clinical symptoms. VIPomas should be diagnosed by elevated plasma VIP combined with increased fecal output (characteristically $>800 \mathrm{~mL} /$ day of fasting). CgA, PP, and glucagon are not of added value to the use of the individual biomarkers for the diagnosis of NF-PNENs. No prospective and/or randomized studies have analyzed the value of individual biomarkers such as $\mathrm{CgA}, \mathrm{PP}$, and glucagon for screening of NF-DPNENs.

\section{Cross-Sectional and Functional Imaging}

Various imaging techniques, for example, computed tomography (CT), magnetic resonance imaging (MRI), and endoscopic ultrasound (EUS), are available and have been suggested for diagnosing, localizing, and the followup of DP-NENs [79]. There is currently a lack of evidence from controlled clinical trials to evaluate the best single or combined methods. The majority of retrospective studies in the literature compare cross-sectional imaging (CT or MRI) to EUS and/or functional somatostatin receptor (SSTR) imaging with and without positron emission tomography (PET) technology.

$\mathrm{CT}$ is the most widely used imaging modality applied to localize tumors. It is to mention that the radiation exposure of $\mathrm{CT}$ has to be taken into consideration, especially if MEN1 patients undergo regular surveillance by CT follow-up examinations.

Several groups have preferred the use of MRI over CT for the screening/imaging of DP-NENs (LE: 3 ) [17, 54, 80, 81]. MRI identifies $>50 \%$ of DP-NENs larger than $30 \mathrm{~mm}$ in diameter, but only $5 \%$ if the tumors are smaller than 10 $\mathrm{mm}[82,83]$. MRI has the advantage of providing homogeneous performance throughout the pancreas. There is no risk of radiation with MRI when compared to other cross-sectional imaging modalities such as CT or PETCT, this being a major advantage of MRI (LE: 3) [17].

NENs express SSTRs that can be targeted with radiolabeled peptides for imaging and treatment [84]. The expression of SSTRs enables new imaging techniques using PET-CT or PET-MRI with radioactively labeled somatostatin analogs (SAs) such as gallium-68 $\left({ }^{68} \mathrm{Ga}\right)$ 1,4,7,10-tetra-azacyclododecane-1,4,7,10-tetra-acetic acid-octreotate (DOTATATE) [85]. Further studies are needed to determine at what age somatostatin-labeled PET-CT/PET-MRI should initially be used and what its place is in the follow-up of patients with MEN1. PET with 
${ }^{68} \mathrm{Ga}$-labeled somatostatin has been suggested to be superior to PET with other tracers in the detection of additional tumors [85-87]. PET with ${ }^{68} \mathrm{Ga}$-labeled somatostatin as a diagnostic modality is recommended [88], providing staging by assessing metastases that can lead to changes in both medical and surgical management strategies (LE: 2b) [89-91]. In growing tumors, imaging should be repeated at least every year, and ${ }^{68} \mathrm{Ga}$-labeled somatostatin PET-CT could be added to the surveillance when tumors $>10 \mathrm{~mm}$ are present and/or are growing to identify metastasis in a timely fashion [92]. However, future prospective studies will be needed to validate these surveillance programs in patients with DP-NENs and MEN1 with regard to modality and interval.

Combining glucagon-like peptide-1 receptor (GLP1R) imaging with morphological cross-sectional imaging (CT or MRI) is a helpful tool in differentiating insulinomas from other P-NENs present in MEN1 patients. Therefore, GLP-1R imaging may guide successful surgical intervention [93].

\section{Selective Arterial Calcium Stimulation and Venous}

\section{Sampling}

Arterial calcium stimulation with hepatic vein catheterization can be used in selected patients when F-DPNENs such as insulinomas (selective arterial calcium injection [SACI]) or gastrinomas (selective arterial calcium or secretin injection) are undetected on cross-sectional imaging $[94,95]$. However, this very invasive technique is only able to regionalize but not to localize hormone excess.

Minimal Consensus Statement on Cross-Sectional and Functional Imaging as Methods to Diagnose and Follow-Up DP-NENs

Detection of DP-NENs, measurements of size, evaluation of progression, and presence of metastatic disease are key elements in the management of patients with MEN1 to determine appropriate therapeutic strategies. In crosssectional imaging (CT, MRI), PNENs are hypervascular lesions. CT is the most widely used imaging modality applied to localize NENs. The radiation exposure of CT has to be taken into consideration, especially as MEN1 patients undergo regular surveillance. MRI should be applied first and achieves excellent results for the detection of DP-NENs with low radiation exposure. MRI and (if available) EUS should be used complementarily for the workup of patients with MEN1. For staging and clinical manage- ment purposes, functional imaging using PETCT/ PET-MRI targeting SSTRs seems to add valuable information. Combining GLP-1R imaging with morphological cross-sectional imaging (CT or MRI) is a helpful tool in differentiating insulinomas from other PNENs present in MEN1 patients. Therefore, GLP-1R imaging may guide successful surgical intervention. In terms of follow-up regimens, surveillance programs should focus on identifying the course of disease in patients with DPNENs. The frequency of screening should be individually adapted for the growth rate. Selective application of calcium into pancreatic arteries and determination of insulin or gastrin in the effluent of the hepatic veins may regionalize but not definitively localize an undetected insulinoma or gastrinoma.

\section{Endosonography/Fine-Needle Aspiration}

Biopsy/CNB

Compared with CT revealing a sensitivity of $81 \%$ and a positive predictive value of $97 \%$ for P-NENs, EUS had $100 \%$ sensitivity and positive predictive value [92], with a close correlation between the largest lesion seen on EUS and pathology [24]. However, EUS frequently overestimates the size of MEN1 DP-NENs, especially those with a size $<20 \mathrm{~mm}$ [96].

Several relatively small studies in patients with MEN1 previously suggested that EUS is a very sensitive method for the early imaging of P-NENs [23, 47, 97-99] and recommended EUS as the first-choice pancreas imaging technique in patients with MEN1 as being the most sensitive imaging modality for NF-P-NENs, detecting lesions as small as $2 \mathrm{~mm} \mathrm{[24].}$

However, EUS is limited by availability, invasive, timeconsuming, and operator-dependent, especially in patients with MEN1, in whom complete pancreatic examination is necessary [23]. EUS has a decreased sensitivity in the pancreatic tail. Also, many small NF-P-NENs without therapeutic consequences are detected, with the necessity of follow-up and resulting in a possible psychological burden.

EUS was seen to be superior to CT or MRI pancreatic lesion detection $[22,100]$. However, a significant proportion of clinically relevant NF-P-NENs $>20 \mathrm{~mm}$ was missed by MRI as well as by EUS. Therefore, it was concluded that to ensure maximum sensitivity, both EUS and MRI can be used alternately to detect lesions, should be used as early as possible, and that if combined, these 2 modalities could reduce the burden of invasive EUS [92]. Because of the limited ability to detect metastatic disease, 
EUS should always be coupled with SRS, which is the most reliable method for detecting metastases [47, 98]. No precise recommendations are available in the literature regarding whether and when to perform EUS-fineneedle aspiration biopsy (FNAB) to confirm the suspicious diagnosis and to grade $\mathrm{P}-\mathrm{NENs}$ in patients with MEN1.

Minimal Consensus Statement on Endosonography/ FNAB as Methods to Diagnose and Follow-Up DP-NENs

Among all available diagnostic imaging modalities, EUS is the most sensitive for the diagnosis of DP-NENs and should be used as the test of choice if a specialized endosonographer is available (LE: 2b, GR: C). EUS is an invasive and not widely available technique, and therefore, MRI is a suitable alternative. Because of the limited detection capability of EUS in terms of metastatic disease, nuclear imaging techniques (SRS), which are the most reliable method for detecting metastases, should also be performed (LE: 4, GR: C). EUS-FNAB should not be routinely performed and should be reserved for firm indications or for cases in which there is diagnostic uncertainty (LE: 5, GR: D). Surveillance EUS is recommended to assess changes in tumor diameter and to evaluate for newly developed lesions (LE: 4, GR: D).

\section{Indications for Surgery}

\section{Is Size the Issue?}

The current recommendation for surgical resection in NF-DP-NENs has been based on tumor size, as a higher rate of metastases was found in patients with larger tumors [30, 101, 102]. Previous guidelines [79] suggested to consider surgical resection for NF-P-NENs that are larger than $10 \mathrm{~mm}$ in size, as do the Uppsala group [103], the Marburg group [104], and the MEN consortium in Japan [105]. The National Comprehensive Cancer Network in the USA has suggested surgical resection in tumors larger than $10-20 \mathrm{~mm}$ in size and in tumors with a relatively rapid rate of growth over 6-12 months (www.nccn.org, version 1.2019).

There are currently several different recommendations for the management of MEN1 patients with small NF-DP-NENs $[106,107]$. In their retrospective analysis of the French Groupe d'étude des Tumeurs Endocrines (GTE) database, Triponez et al. [30] showed that the risk of death was low for patients with small $(<20 \mathrm{~mm})$ NFDP-NENs. Those authors proposed a conservative attitude for patients in the absence of other aggressive features, such as rapid progression on imaging studies [30, 108]. A recent study by the GTE assessed the distant metastatic potential of NF-DP-NENs and confirmed the former recommendations by Triponez and colleagues [30, 109] concluding that DP-NENs $>20 \mathrm{~mm}$ should be removed to prevent metastasis and increase survival, regardless of their associated secretion (LE: 2b) [110].

With regard to F-DP-NENs, the treatment for nonmetastatic gastrinomas located in the duodenum is surgical excision, as disease-related survival in patients with tumors even larger than $20 \mathrm{~mm}$ has been seen to improve after surgery (LE: 3) [111]. Most gastrinomas are multiple and occur within the duodenum, and most centers undertake nonsurgical management unless the NENs (suspected to be gastrin producing) are pancreatic and/or larger than $20 \mathrm{~mm}$, in which case surgery is recommended. The prognosis of gastrinoma has been associated with tumor size and the presence of hepatic metastases [112]. Some groups recommend a more aggressive approach if the biochemical diagnosis is unequivocal and distant metastases are absent in order to prevent metastatic spread (LE: 3) [104, 113, 114]. Regardless of their size, the resection of insulinomas, VIPomas, and glucagonomas is recommended.

\section{Minimal Consensus Statement on Size as an Indication for Surgery of DP-NENs}

The risk of progression in DP-NENs is linked to size (LE: 4). NF-DP-NENs smaller than $20 \mathrm{~mm}$ can be followed conservatively in the absence of an aggressive family history or signs of malignancy documented by imaging or biopsy of metastasis. NF-DP-NENs within MEN1 larger than $20 \mathrm{~mm}$ should be resected surgically. Most gastrinomas are multiple and occur within the duodenum, and most centers undertake nonsurgical management unless the NENs (suspected to be gastrin-producing) are pancreatic and/or larger than 20 $\mathrm{mm}$. Regardless of their size, surgery is recommended for insulinomas, VIPomas, and glucagonomas.

\section{Is Tissue the Issue?}

DP-NENs in MEN1 patients develop from multiple, clonally unrelated tumors. While macroscopically, an average of 5 DP-NENs [49] has been described in patients undergoing surgery, the number of microscopically detectable tumors is much higher because of the multifocal- 
ity of the disease [115]. A subset of these tumors develops the ability to grow to a detectable size and to become clinically relevant.

At the moment, the underlying mechanisms are not understood well enough to predict which tumors will undergo progression. Such progression involves secondary mutations such as those of the death domainassociated protein gene/alpha thalassemia/mental retardation syndrome in a subset of tumors [116]. In the setting of MEN1 disease, these mutations have been shown to occur exclusively in rare MEN1-associated DP-NENs $>30 \mathrm{~mm}$ [116].

NENs larger than $20 \mathrm{~mm}$ have more chromosomal aberrations than small P-NENs. The mechanisms involved could include epigenetic changes. Besides size, a second prognostic factor is grading assessed by proliferation (Ki67 ) or mitotic index. Tumor size of $\geq 20 \mathrm{~mm}$ seems to correlate with more aggressive MEN-1-related pancreatic disease, and P-NENs graded as G2 should be treated surgically regardless of their size $[115,117]$.

The term "neuroendocrine neoplasm" was used synonymously with "neuroendocrine tumors" in many older and more recent publications. In 2018, the WHO published a uniform classification framework for all NENs. The key feature of the new classification is a distinction between "well-differentiated" neuroendocrine tumors (NETs) and "poorly differentiated" neuroendocrine carcinomas (NECs), as they both share a common expression of neuroendocrine markers. NENs may be graded as NET G1 (low grade), NET G2 (intermediate grade), or NET G3 (high grade) based on mitotic count and/or Ki67 labeling index and/or the presence of necrosis. NECs are considered "high grade" by definition [118].

Minimal Consensus Statement on Tissue as an Indication for Surgery of DP-NENs

The risk of progression in DP-NENs is linked to proliferation (grading) (LE: 4-5). When DP-NENs reach the size cutoff ( $20 \mathrm{~mm}$, leading tumors), it may be recommended to obtain tissue specimens of those tumors to select patients at risk of highly proliferating NENs and who may require early surgical intervention to prevent invasive growth, regional and distant metastases. DP-NENs graded as G2 should probably be given early-stage surgery, regardless of their size.

\section{Is Genetics the Issue?}

Three recent studies tended to show that the tumor aggressiveness of P-NENs may be related either to the loss of interaction of menin with functional partners - JunD proto-oncogene (JunD) and checkpoint suppressor 1 (CHES1) - or to mutations in exon 2. On the one hand, mutations affecting the JunD-interacting domain seemed to be associated with a higher risk of death secondary to a MEN1 tumor in a cohort study with 806 patients (LE: 2b) [119]. On the other hand, a higher risk of aggressive P-NENs in patients with MEN1 mutations affecting the CHES1-interacting menin domain was established in a 67-patient series (LE: 3) [120].

Only 1 recent publication has established a genotypephenotype correlation in MEN1 disease. An increased prevalence of DP-NENs was found in a series with 188 MEN1 patients when a mutation in exon 2 was present (LE: 2b) [121]. The study described a 2-fold increased risk of metastasis among patients between 20 and 40 years of age when a mutation in exon 2 was found, knowing that the JunD domain is partially included in exon 2 (LE: 2b) [121]. These investigators advised to decrease the size recommendation for DP-NEN resection to $\geq 15$ $\mathrm{mm}$ for exon 2-mutated patients; yet, they also suggested that confirmation be obtained from other independent studies.

Two specific mutations associated with aggressive DPNENs may be considered to affect the final decision for pancreatic surgical resection when the indication is questionable. Aggressive phenotypes with a high penetrance of malignant P-NENs within particular families have been reported (LE: 4 [122]; LE: 4 [123]). Both of the families analyzed in these reports carried germline mutations that completely abolished menin function. Belonging to this type of family is a reasonable additional factor in the process of final surgical decision-making. Further international cooperative studies are required before recommendations on this topic can be established, even though the indications for a possible genotype-phenotype correlation are promising.

Minimal Consensus Statement on Genetics as an Indication for Surgery of DP-NENs

The risk of progression in DP-NENs seems to be linked to genetic factors (LE: 5). There is still no clear evidence of a genotype-phenotype correlation regarding DP-NENs in MEN1 disease. 


\section{Surgical Treatment}

\section{Surgical Strategies}

Surgery for F- and NF-DP-NENs requires a multidisciplinary approach with the patient at the center. Surgical resection of F-DP-NENs is generally recommended as long as diffuse unresectable metastatic disease is excluded. The goals of the initial operation of NF-DP-NENs are to preserve patients' quality of life, prevent further progression or dissemination of disease, and provide as long a period as possible before any subsequent pancreas intervention (LE: 3, GR: B).

\section{Gastrinoma (MEN1-ZES)}

MEN1 gastrinoma (provoking ZES) is the most frequent F-DP-NEN (30\%). Gastrinomas in MEN1 are duodenal in origin. Therefore, all patients with MEN1-ZES have gastrinomas in the duodenum (LE: 2b) [114, 124126]. P-NENs, which may exist besides the gastrinoma in MEN1, are in the majority NF-NENs. Regardless of their size, the majority of gastrinomas exhibit malignant biological behavior.

The management of MEN1 gastrinoma, be it medical treatment with PPIs or surgery, is a highly controversial issue. At least $70-80 \%$ of MEN1 gastrinomas have been demonstrated to be malignant at the time of diagnosis and to show lymph node and/or liver metastasis, although the primary D-NEN(s) may be microgastrinomas as small as $1-2 \mathrm{~mm}$ in size (LE: 2b) [28, 114, 124, 127, 128]. Recent expert guidelines have suggested medical management using PPIs for most patients since the course of disease is rather mild, even without surgery. Based on the published literature, MEN1-ZES is considered a surgically non-curable disease (LE: 3b) [8].

There is neither consensus on the indication nor on the timing of surgery in MEN1-ZES. Most groups recommend a surgical approach only if the tumor reaches $20-30 \mathrm{~mm}$ in size, as the risk for liver metastases then increases significantly [129-131]. Several groups have recommended surgery for MEN1-ZES if imaging visualizes a pancreatic lesion $>20-30 \mathrm{~mm}$ in size $[110,125,129]$. The correct interpretation of such imageable "pancreatic tumors" (>20 mm) in MEN1ZES has to be related to NF-P-NENs and not to gastrinoma. Nevertheless, the presence of an imageable pancreatic lesion $>20 \mathrm{~mm}$ in MEN1-ZES, although most likely nonfunctioning, may be a useful surrogate parameter to indicate surgery, based on the good rate of long-term survival in this setting of up to $100 \%$ at 10 years (LE: 2b) [110, 125].

Multiple Endocrine Neoplasia Type 1 and the Pancreas
Likewise, there is no consensus regarding the type and extent of surgery for MEN1-ZES. Most experts agree that NF-P-NENs besides D-gastrinoma should be either enucleated, whenever technically feasible, or removed by formal pancreatic resection, both combined with systematic lymphadenectomy [132]. Total (duodeno)pancreatectomy (TP) as an initial procedure for MEN1-ZES should be avoided whenever possible, since resulting "brittle" diabetes (unstable diabetes) significantly reduces patients' quality of life and is associated with serious morbidity during long-term survival. Completion pancreatectomy should be avoided if technically possible and justified from an oncological perspective. Any type of DP resections for MEN1-ZES should only be performed by experienced pancreatic (endocrine) surgeons.

Approximately $24 \%$ of patients with MEN1-ZES develop an aggressive course of disease with distant metastases, leading to death (LE: 2a) [133]. No reliable marker or parameter has so far been identified to indicate an aggressive course of disease in MEN1-ZES. The most important determinant of survival in patients with MEN1ZES is the presence or development of hepatic metastases $[130,131,133]$. At present, there are insufficient data for MEN1-ZES to unequivocally determine in which patient cytoreductive surgery for liver metastases should be performed. Hyperparathyroidism-related hypercalcemia may increase gastric acid output and hyperparathyroidism should be corrected before treating MEN1-ZES [134].

\section{Minimal Consensus Statement on Surgical Strategies for Gastrinoma (MEN1-ZES)}

There is no consensus on the indication for surgery, since no parameter has been shown to indicate an aggressive course of disease, and long-term survival is excellent in about $75 \%$ of patients, even without surgery. The higher chance of cure when performing a pancreaticoduodenectomy (PPD) resection at the time of biochemical ZES evidence, even without positive imaging, should be discussed with the patient in terms of benefits and risks. It is consensus that any operation should include an exploration of the duodenum via duodenotomy or even resection of the duodenum combined with systematic lymphadenectomy to provide a chance to cure hypergastrinemia and to reduce the risk of distant metastatic disease. Based on the very limited data, it is recommended that the indication for reexploration in MEN1-ZES should be considered with caution, especially since the symptoms can be well controlled with medical treatment and long-term survival without dis-

Neuroendocrinology 2021;111:609-630 617 
tant metastases is excellent. The surgical procedure should be individualized according to preoperative findings, previous DP resections, the patient's history (e.g., age and preexisting insulin-dependent diabetes), and the patient's preference. Surgery may be considered in MEN1-ZES patients with advanced disease confined to the liver if at least $90 \%$ or all of the identifiable tumor burden can safely be removed. It is recommended to treat hyperparathyroidism before treating MEN1-ZES.

\section{Insulinoma}

MEN1 insulinoma is the second most frequent F-DPNEN (15\%). The target organ of insulinoma is the pancreas. Insulinomas (endogenous [organic] hyperinsulinism provoking the hypoglycemic syndrome) are distributed over the entire pancreas. The size of insulinomas varies from a few millimeters to centimeters. Multiple insulinomas are found in up to $30 \%$ patients with MEN1. An indication for surgery is generally advocated because of the lack of effective alternative medical treatment. The majority (>90\%) exhibit benign biological behavior.

The precise localization of insulinoma within multiple DP-NENs seems useful in assisting to plan individual surgical (tissue-preserving) procedures. It is sometimes difficult to distinguish insulinomas from other additionally existing P-NENs by pre- or intraoperative imaging techniques (EUS/CT/magnetic resonance tomography/PETCT or PET-MRI) or by "regionalization" procedures (SACI). The possibility to classify a P-NEN as insulinoma must theoretically be entrusted to specific diagnostic techniques. EUS-guided FNB could be a rational approach to localize insulinomas but has until now been rarely employed $[21,135,136]$.

GLP-1R imaging by ${ }^{68} \mathrm{Ga}$-exendin-4 PET/CT has been recently seen to correctly localize insulinomas in almost all patients affected by MEN1 insulinomas [93]. Although GLP-1R PET-CT promises to selectively detect insulinomas, more experience is presently needed to validate this new imaging technique in a large number of MEN1 patients. Applying the SACI test, insulinoma cannot be "localized" definitively in the pancreas, but small NENs can be "regionalized" in the pancreas, assigning the insulinsecreting lesion to the right or left pancreatic region after $\mathrm{SACI}$ in the main pancreatic arteries with hepatic venous sampling for insulin [94].

The absence of prospective, controlled studies makes the choice of the type of surgery uncertain. An individualized approach is recommended, based on the location and size of the suspected insulinoma. In cases of a solitary tumor or 1 dominant tumor $(>10 \mathrm{~mm})$ besides few other small DP-NENs $(\leq 5 \mathrm{~mm})$, enucleation or segmental pancreatic resection with the dominant tumor(s) is recommended with the advantage of avoiding postoperative complications and negative long-term results, such as diabetes, persistence of organic hyperinsulinism [137], or recurrence of hypoglycemia (LE: 4) [50, 138].

In selected patients with the insulinoma localized in the pancreatic (body or) tail, distal pancreatectomy with/ without enucleation of additional NENs in the pancreatic head ("Thompson procedure") is recommended. PPD with or without pylorus preservation is rarely employed and may be indicated in patients with large insulinoma involving most of the pancreatic head and independent of size in 1 or more tumors located deep in the pancreatic tissue close to the main pancreatic duct.

\section{Rare F-DP-NENs}

Less than 3\% of P-NENs secret VIP (VIPoma), glucagon (glucagonoma), or somatostatin (somatostatinoma) [28]. All these NENs arise in the pancreas with the exception of somatostatinoma, which may also be located in the duodenum or in the first jejunal loop. Visceral metastases (with the highest prevalence in the liver) are usually documented if the tumor dimension exceeds $30 \mathrm{~mm}$ and may be the cause of death in approximately half of the affected patients. The 10-year survival rates approach $50-60 \%[28$, 37].

Even at an advanced stage, surgery is recommended $[28,37]$. Surgical exploration must be carried out with the intention to perform radical resection of the primary tumor and eventually its metastases. The type of pancreas resection is related to tumor localization. Both PPD and distal pancreatectomy are required, and TP may usually be omitted. Extensive lymphadenectomy is useful, especially for somatostatinoma and glucagonoma, which have a propensity for lymph node spread. Surgical resection of hepatic metastases may be indicated (LE: 4).

Minimal Consensus Statement on Surgical Strategies for Insulinoma (Organic Hyperinsulinism)/Rare F-DP-NENs

There is a general recommendation to operate insulinoma because of the lack of effective medical treatment. An individualized approach is recommended, based on the location and size of the suspected insulinoma, which has a high probability to cure hyperinsulinism and which preserves the exocrine and endocrine pancreatic functions at a high rate. In cases of a solitary 
tumor or 1 dominant tumor $(>10 \mathrm{~mm})$ besides some other small DP-NENs ( $\leq 5 \mathrm{~mm}$ ), enucleation or segmental pancreatic resection with the dominant tumor(s) is recommended whenever technically feasible. Larger insulinomas located in the pancreatic tail, especially adjacent to the main pancreatic duct, should be treated by distal pancreatic resection to reduce complications (e.g., pancreatic fistula) and preserve the spleen. Enucleation of additional NENs in the pancreatic head is recommended. Surgery is indicated in VIPoma, glucagonoma, and somatostatinoma, even if only tumor debulking is possible.

\section{$N F-D P-N E N s$}

The focus of NF-DP-NEN management is currently on the prevention or delay of death from malignancy, balancing the risks of disease against the effects of complex pancreatic surgery. The indication to treat surgically asymptomatic NF-DP-NENs depends on the initial size, imaging findings (signs of invasion, regional, and/or distant metastasis), and the further growth rates of borderline-size tumors during follow-up. Since MEN1 is a hereditary disease affecting the neuroendocrine pancreas, DP-NENs can always recur unless the entire gland is removed.

An important area of debate over the last 2 decades has been the identification of triggers for malignant behavior of NF-DP-NENs and thereafter for surgical intervention. Initial pancreatic surgery should be tailored to the patients' clinical situation, the sites of disease within the pancreas, and the biological characteristics of the NEN. It should be the intent of surgery to remove all of the demonstrable tumors from the pancreas and duodenum while preserving pancreatic parenchyma to maintain normal endocrine pancreatic function.

Striking a balance between the timing and extent of a given surgical procedure, the attendant risk of complications and risk to life of the DP-NEN is complex, with limited outcome data on which to base treatment recommendations [139]. The current indications for surgery are NF-DP-NENs $>20 \mathrm{~mm}$ or those $<20 \mathrm{~mm}$ with significant growth under surveillance to prevent or delay death from malignancy $[49,140]$. If surgery is indicated, the most common operation is a distal pancreas resection with enucleation of tumors in the proximal pancreas or duodenum (Thompson procedure; [141]). This strategy appears to delay, but not completely eliminate, recurrences, reoperations, and deaths from DP-NEN, while preserving some pancreatic parenchyma for endocrine function. The alternative of TP has mainly been employed when

Multiple Endocrine Neoplasia Type 1 and the Pancreas that is required for complete tumor resection or in recurrent NF-P-NENs in the pancreatic remnant [142].

In a systematic review and exploratory meta-analysis of the literature (see online suppl.), tumor enucleation conferred similar survival rates to major pancreatic resection. However, the former is associated with a lower risk of postoperative endocrine insufficiency and a higher risk of recurrence but not reoperation. At any rate, the significant heterogeneity identified in the reporting of these data necessitates large, multicenter, prospective, and comparative studies with long-term follow-up to allow a definitive conclusion as to whether the initial surgical intervention for MEN1-associated NF-DP-NENs should be enucleation or resection. The available data suggest that the former, where it can be safely performed, is probably the better option [143].

Minimal Consensus Statement on Surgical Strategies for (Asymptomatic) NF-DP-NENs

Surgery for NF-DP-NENs in MEN1 is indicated in patients with tumors that measure $>20 \mathrm{~mm}$ or tumors with progression under surveillance (LE: 3; GR: B). Striking a balance between the timing and extent of a given surgical procedure, the attendant risk of complications and risk to life of P-NENs is complex, with limited outcome data on which to base treatment recommendations. Initial pancreatic surgery should be tailored to the sites of disease within the pancreas and the patient's clinical situation. The goals of the initial operation are to preserve patient's quality of life, prevent further progression or dissemination of disease, and to provide as long a period as possible before any subsequent pancreas intervention (LE: 3, GR: B).

\section{Laparoscopic/Robotic Surgical Techniques}

Endoscopic procedures can be performed safely with the potential patient benefit of successful minimally invasive surgery (LE: 2b) [144-146] and may be applied if the same radical extent of surgery (primary tumor, lymph nodes; with/without splenectomy) is feasible as when performing open procedures or in selected patients with a palliative intention.

Laparoscopic enucleation and/or spleen-preserving DP resection can be applied in insulinoma and NF-DPNENs $\leq 20 \mathrm{~mm}$ and is the treatment of choice [147]. Extended lymph node dissection is not recommended in these situations because of an overall low malignant potential. In all F-DP-NENs and in NF-DP-NENs $>20 \mathrm{~mm}$ 
with a higher malignant potential or when malignancy is confirmed, oncologically appropriate lymph node dissection is mandatory. In experienced hands, this procedure can be performed laparoscopically [144].

Approximately $80 \%$ of MEN1 gastrinomas located multiply in the duodenum have lymph node metastases at the time of diagnosis, necessitating lymphadenectomy and frequently showing accompanying P-NENs, which also require treatment. Any type of endoscopic mucosal resection or resection without lymph node dissection seems oncologically inadequate [114]. The laparoscopic approach may only be performed if the gastrinoma is preoperatively well localized in the anterior duodenal wall (LE: 4) [148] and the surgeon is familiar with the techniques of laparoscopic peripancreatic lymphadenectomy.

In the presence of potentially multiple insulinomas or multiple NF-DP-NENs, the majority of endocrine surgeons favor an extended exploration of the entire gland in open surgery. However, laparoscopic approaches may be applied in selected patients by surgeons highly experienced in endoscopic procedures. Experience with intraoperative EUS is mandatory to better localize the NEN within the pancreatic tissue.

Overall, the available evidence for endoscopic procedures (with/without robots) in the treatment of MEN1 DP-NENs is very limited. There are only "case reports" published as "expert opinions without explicit critical appraisal” (LE: 5; GR: D). Laparoscopic and robotic PPD resections may be feasible and safe (LE: 3), yet they are technically demanding $[149,150]$.

\section{Minimal Consensus Statement on Laparoscopic/ Robotic Surgical Techniques}

Laparoscopic enucleation and/or spleen-preserving DP resection (with/without robotic assistance) can be applied in insulinoma and NF-DP-NENs $\leq 20 \mathrm{~mm}$ and is technically feasible and the current procedure of choice. In all FDP-NENs and in NF-DP-NENs $>20$ $\mathrm{mm}$ with a higher malignant potential or when malignancy is confirmed, oncologically appropriate lymph node dissection is mandatory. In experienced hands, this procedure can be performed laparoscopically. Endoscopic local excision of duodenal gastrinomas with laparoscopic extended lymph node dissection should not be performed. Final recommendations for laparoscopic surgery cannot be given for MEN1.

\section{Advanced Local and Distal Disease}

There are no clear recommendations with respect to the indication, timing, and type of palliative pancreatic surgery in locally advanced disease or in MEN1 patients with unresectable hepatic metastases. The indication for palliative local and distal surgery should always be discussed within a multidisciplinary team considering all therapeutic (alternative) options and should be recommended for tumors refractory to nonsurgical treatments [151]. Patients may benefit from local radical resection of lymph node and distant metastasis [152].

Possible prognostic benefits may be expected in MEN1 patients after surgical resection of the primary, even in the presence of disseminated liver metastasis [153]. Surgery should be carried out to yield a low morbidity rate and be performed in high-volume referral centers [154-158].

Palliative surgery may be recommended in F- and NFDP-NENs with advanced local or distant disease confined only to the liver if at least $90 \%$ or all of the identifiable tumor burden can safely be removed. Liver metastases in MEN1 patients are bilobar in $80 \%$ of the subjects. In the case of surgical resection of liver metastasis, the probability to achieve an R0 resection in the liver is low (approximately $10 \%)[88,154-156,159]$.

Minimal Consensus Statement on Surgery in Fand NF-DP-NENs with Advanced Local and Distal Disease

The indication for palliative local and distal surgery should always be discussed within a multidisciplinary team considering all therapeutic (alternative) options and should be recommended for tumors refractory to nonsurgical treatments [151]. Local radical surgery for F- and NF-DP-NENs with unresectable liver metastases can be indicated in selected cases with well-differentiated (G1) or moderately differentiated (G2) tumors in the absence of extrahepatic metastases and peritoneal spreading to reduce local tumor burden (LE: 3; GR: B). The potential benefits of cytoreductive (debulking) surgery in patients with locally resectable FDP-NENs and unresectable liver metastasis are to provide relief from the symptoms of hormonal excess, to limit the disease to the liver, and to prevent life-threatening and obstructive complications such as bleeding, acute pancreatitis, jaundice, or intestinal occlusion (LE: 3; GR: B) [55, 160, 161]. In patients with G1 or G2 F- and NF-P-NENs, resectable liver metastases, and no extrahepatic metastasis, liver resection should be considered as the primary treatment [88]. 


\section{Natural Course - Conservative Treatment}

Natural Course of Untreated NF-DP-NENs

(Asymptomatic) and Follow-Up Protocols of Treated

DP-NENs

Besides thymic NENs, metastatic DP-NENs are the most important disease-related cause of death in patients with MEN1. Therefore, consequent follow-up examinations are mandatory to prevent progressive disease. The high prevalence and variable malignant potential of Fand NF-DP-NENs decreasing patients' life expectancy outline the need for consistent follow-up protocols. Management decisions should be made in a multidisciplinary team and MEN1 patients should be followed individually by experts [162].

As a result of the genetic background, F- and NF-DPNENs may recur, grow, and metastasize $[27,39,163,164]$. The most important prognostic factors to be used in follow-up and as a consequence of clinical decision-making in MEN1-related NF-DP-NENs are tumor size, grading (mitotic count/Ki-67 index), and the annual growth rate $[30,49,109,117]$. Based on the available evidence documenting an overall indolent nature of NF-DP-NENs especially in NENs $<20 \mathrm{~mm}$, intensive follow-up does not seem to be necessary once it is established that tumors do not show a tendency toward rapid growth, and the frequency of DP-NENs imaging might be decreased (LE: 2a and 4). The annual growth rate of NF-DP-NENs, as measured by means of EUS and conventional imaging (MRI/ CT scan), was seen to vary between 0.1 and $1.32 \mathrm{~mm}$ per year [92]. Larger tumor size seems to be associated with a higher rate of metastasis and a decrease in overall survival $[27,30,42,165]$.

In a Dutch cohort study, $>80 \%$ of the DP-NENs were WHO grade $1,16 \%$ WHO grade 2 , and only one of the tumors was a WHO grade 3 NEN [165]. Grade 2 NF-DPNENs should be considered high risk [117]. A high Ki-67 index/mitotic count in large $(>20 \mathrm{~mm})$ NF-DP-NENs was associated with poor prognosis. This association was not seen for WHO grade based on Ki-67 [165]. Irrespective of the indolent course of most DP-NENs, liver metastasis develops in 15-19\% of the patients suffering from NF-DP-NENs $[27,129]$. The presence of liver metastasis is the most important prognostic factor related to overall survival in patients with MEN1-related DP-NENs [27, 31, $42,46,129]$.

From the moment of diagnosing DP-NENs in patients without liver metastasis, the 5- and 10-year survival rates were 95 and 86\%, respectively, compared to 65 and 50\% for patients with liver metastasis [42]. Optimal radiologi-

Multiple Endocrine Neoplasia Type 1 and the Pancreas cal follow-up of NF-DP-NENs has not yet been established [92]. EUS has the highest sensitivity in detecting new NF-DP-NENs. A combined strategy of EUS and MRI seems to be the most useful. However, MRI seems to be cost-effective for follow-up and could be alone utilized in patient surveillance. Functional imaging (e.g., with ${ }^{68} \mathrm{Ga}$ octreotate DOTA PET-CT) could be added if NF-DPNENs are diagnosed to identify metastasis during followup [92].

Even when measured in combination, the tumor markers PP, CgA, and glucagon are not helpful in MEN1 DP-NEN screening and follow-up programs [92]. However, it seems plausible that after a DP-NEN is diagnosed, the markers can be used for follow-up as a proxy for measuring increase in tumor load or biochemical activity (LE: 5).

\section{Consensus Statement on the Natural Course of Untreated NF-DP-NENs (Asymptomatic) and Follow-Up Protocols of Treated DP-NENs}

Follow-up management should be individualized and based on various expert opinions. Initial tumor size, grading (mitotic count/Ki-67 index), and the annual growth rate influence the follow-up strategies. The annual growth rate varies between 0.1 and 1.32 mm per year. A high Ki-67 index/mitotic count in large $(>20 \mathrm{~mm})$ NF-DPNENs is associated with poor prognosis. No studies in MEN1 patients have so far focused on the usefulness of the tumor markers PP, CgA, and glucagon for the follow-up of known tumors. Controversies exist regarding the value of various biochemical and radiological follow-up tests. A consensus for optimal radiological or EUS screening has not yet been established. Based on the indolent nature of small $(<20$ $\mathrm{mm}$ ) DP-NENs, intensive follow-up does not seem to be necessary once it is established that tumors do not show a tendency toward growing and frequency of DPNENs imaging might be decreased (LE: $2 \mathrm{a}$ and 4). Liver metastases are the most important prognostic factors related to overall survival with 5- and 10-year survival rates around 65 and 50\% compared to patients without liver metastasis with 95 and $86 \%$ rates.

\section{Medical Treatment Options}

\section{F-DP-NENs}

Curative surgery is always the initial treatment of choice and may theoretically solve the hormone excess 
involved in removing a given F-DP-NEN. To stabilize hormone excess, medical therapy and therapies directed against the functioning tumor to prevent hormone-associated complications are sometimes needed prior to surgery. To the same end, it is needed in patients with persisting or recurrent hormone excess after local surgical procedures, as well as those with functioning (unresectable) distant metastasis (LE: 2b) [28, 31, 63, 79, 166, 167].

\section{Gastrinoma and ZES}

In MEN1-ZES patients, gastric acid hypersecretion is almost universally present at diagnosis [168-170], and older studies demonstrated very high complication rates and high mortality if such hypersecretion is not under control [31, 140, 167, 171, 172]. Prior to the development of gastric acid antisecretory drugs effective in ZES, the principal cause of death in MEN1 patients was complications of the gastric acid hypersecretory state, not the malignant nature of the tumor itself $[28,31,140,167,168]$. After extended surgical resection, the state of hormone excess may remain a problem, as patients with MEN1ZES are rarely cured $[28,55,138,173-175]$.

The drugs of choice to control gastric acid hypersecretion are PPIs (e.g., omeprazole, lansoprazole, pantoprazole, esomeprazole, and rabeprazole) (LE: 2a) [63, 176178]. SAs have also been applied to control acid secretion by reducing circulating gastrin levels. Although PPIs are first-line options for symptom control, they can be complemented by adding SAs [179].

\section{Insulinoma}

Diazoxide, a non-diuretic thiazide analog, has potent hyperglycemic effects on insulinoma. In MEN1 patients with insulinomas prior to surgery, hypoglycemia is also controlled by frequent feedings [71, 77, 180, 181]. At times, the use of long-acting SAs (lanreotide or octreotide) is recommended $[71,77,180,181]$.

Glucagonoma, VIPoma, and Somatostatinoma

In other F-DP-NENs (such as glucagonomas, VIPomas, and somatostatinomas), the hypersecretory state sometimes associated with severe electrolyte shifts needs to be acutely managed prior to any other treatment directed against the F-DP-NENs (LE: $2 \mathrm{~b}$ ). With regard to these rare F-DP-NENs, the drugs of choice for the acute and long-term control of the hypersecretory state are long-acting SAs in patients with unresectable VIPomas, glucagonomas, and in the small number of clinically peculiar patients with somatostatinomas $[71,179]$.
Hypercalcemia of primary hyperparathyroidism makes it sometimes difficult to medically control the hormone excess state, especially in patients with MEN1-ZES. If parathyroid surgery is not possible, medical treatment of hyperparathyroidism should include the administration of calcium-sensing receptor agonists such as cinacalcet $[182,183]$.

\section{Minimal Consensus Statement on Conservative (Medical) Treatment Options for F-DP-NENs}

Medical treatment of the hormone excess states in MEN1 patients with F-DP-NENs is similar to that recommended for patients with sporadic F-DP-NENs. Antisecretory drug requirements can change with time, and patients with ZES are recommended to have their acid-secretory control checked every 6-12 months. Diazoxide should be initiated at a dose of 3-8 $\mathrm{mg} / \mathrm{kg}$ per day divided into 3 or 4 daily doses. If not effective, the analog can be increased to a maximum daily dose of $15 \mathrm{mg} / \mathrm{kg}$. Because SAs also decrease glucagon and growth hormone secretion, administration may occasionally worsen hypoglycemia and patients should be well controlled before leaving the hospital. In patients with F-DP-NENs and uncured hyperparathyroidism, consideration should thus be given to correcting hyperparathyroidism first, especially if medical control of the hypersecretory state is difficult.

\section{SA Treatment in Small $(\leq 20 \mathrm{~mm})$ NF-(G1/G2) $D P-N E N s$}

Although several studies have demonstrated that NFDP-NENs $\leq 20 \mathrm{~mm}$ yield a low oncological risk and that progression-free survival may be identical in patients undergoing active surveillance compared to surgery [30, $184]$, concerns over unpredictable tumor progression or the development of distant metastases affect patients as well as their referring physicians, not only following active surveillance. Experience with SAs in MEN1 DPNENs is limited as to the development of new DPNENs, tumor growth, and the development of lymph node and/or distant metastasis during surveillance, and no final recommendations can thus be given [185-187].

In a preliminary study, Faggiano et al. [188] evaluated the efficacy of SA Lanreotide Autoge ${ }^{\circledR}$ (LAN group) in a prospective study comparing patients in the LAN group and patients in the group with active surveillance not receiving any therapy (AS group). In the LAN group, single patient had an objective tumor response, the majority had 
stable disease, and the minority had tumor progression. In the AS group, NEN progression was documented in the majority of subjects.

\section{Biotherapy - Targeted Therapy - Radiotherapy - Liver-Directed Therapy}

The treatments for locally advanced and/or metastasized and therefore unresectable/non-curable F- and NFDP-NENs related to MEN1 include biotherapy (e.g., SAs, inhibitors of receptors and monoclonal antibodies), chemotherapy, and radiological therapy [189]. However, there is a lack of clinical trials with a greater number of MEN1 patients with DP-NENs but instead various case reports revealing the efficacy of these treatment regimens.

\section{Advanced F-DP-NENs}

Long-acting SAs have been seen to control hypoglycemia in a number of "malignant" insulinomas $[190,191]$. Everolimus has recently demonstrated significant efficacy in controlling hypoglycemia in patients with metastatic insulinomas refractory to other therapies [192].

In glucagonoma, cytotoxic treatments with streptozotocin plus 5-fluorouracil (5-FU)/doxorubicin or temozolomide plus/minus capecitabine are valid alternatives to everolimus and sunitinib. This type of tumor is also sensitive to peptide radioreceptor therapy (PRRT) with lutetium-177 $\left({ }^{177} \mathrm{Lu}\right)$-DOTATATE and yttrium-90 $\left({ }^{90} \mathrm{Y}\right)$ 1,4,7,10-tetra-azacyclododecane-1,4,7,10-tetra-acetic acidTyr3-octreotide (DOTATOC). Everolimus is also quite effective in VIPoma in controlling the clinical symptoms related to VIP production by reducing circulating VIP levels. Finally, PRRT can be applied in these patients with clinical benefit. The medical treatment for somatostatinoma includes the same type of treatment as for NF-DP-NENs.

\section{Advanced NF-DP-NENs}

Metastatic NF-DP-NENs are commonly given first-line treatment with the cytotoxic agent streptozotocin (plus 5-FU or doxorubicin or temozolomide plus capecitabine). Due to problems in many countries to obtain streptozotocin, more and more patients are now starting on everolimus or sunitinib as first-line medications [200].

Radioactive treatments with SA-based radioactive peptides such as 177Lu and 90Y have been applied with significant efficacy in patients with malignant F-DP-NENs (gastrinomas and insulinomas) and NF-DP-NENs [201, 202]. Radioactive treatment with PRRT has yielded significant clinical benefits in patients with various DPNENs, thus representing a valid alternative to everolimus and sunitinib. Up to now, and with the exception of 4 case reports, there is little experience in applying PRRT in advanced MEN1 F- and NF-DP-NENs as a first-line treatment $[193,194]$.

In these patients, good palliative response to PRRT was observed without any major hematological or renal toxicity. However, the optimal sequencing with targeted drugs and/or chemotherapy and/or PRRT needs to be defined in advanced F- and NF-DP-NENs, also in MEN1, when data from prospective randomized trials with PRRT in DP-NENs become available [151]. Recent preclinical studies have identified potentially new targeted therapeutic options for treating MEN1-associated NENs, such as epigenetic modulators, Wnt pathway-targeting $\beta$-catenin antagonists, Ras signaling modulators, Akt/mTOR signaling modulators, novel SSTR analogs, anti-angiogenicdrugs, and MEN1 gene replacement therapy [195].

\section{DP-NECs (G3)}

In a Dutch cohort study, approximately $1 \%$ of DPNENs within MEN1 was graded as G3 (=NEC) [165]. The important recommendations concerning DP-NENs have recently been summarized and follow the concepts applied to sporadic DP-NECs [196]. For NECs, the guidelines generally summarize that systemic chemotherapy is indicated in advanced inoperable disease, provided that the given patient has adequate organ function and performance status.

\section{Minimal Consensus Statement on Conservative Treatment Options for Small NF-DP-NENs, Locally Advanced F- and NF-DP-NENs, and DP-NECs}

SAs may be effective as antiproliferative therapies in MEN1-related P-NENs $<20 \mathrm{~mm}$, suggesting the use of these compounds to arrest the development of new tumor lesions as well as to delay or avoid pancreatic surgery. Everolimus and sunitinib may be considered now as first-line treatments for advanced NF-DP-NENs, competing with cytotoxic therapies such as streptozotocin plus 5-FU or doxorubicin and/or temozolomide plus/minus capecitabine. PRRT with SA-based agents such as ${ }^{177} \mathrm{Lu}$-DOTATATE and ${ }^{90}$ Y-DOTATOC is recommended after failure of medical therapy. Up to now, the value of PRRT as first-line treatment in advanced F-and NF-DP-NENs seems promising. DPNECs are a domain for medical treatment. The combination of cisplatin and etoposide, or alternative regimens substituting carboplatin for cisplatin or irinotecan for etoposide, is recommended as first-line therapy. 


\section{Medical treatment options}

The concurrence of pregnancy and MEN1 is very rare. There are only 3 cursory case reports of 4 females and MEN1 with gastrinoma or NF-P-NENs before or during pregnancy [197-199]. In all patients, pregnancy and the time after delivery was uneventful considering individual aspects of the functionality, grade, and stage of the DPNENs. They influence the sequence of necessary diagnostic follow-up intervals, as well as the methods, the type, and timing of treatment.

Arguments for and against pregnancy are to be discussed with the patient and her family. Because of the rarity, there are no guidelines on how to advise young females with genetically confirmed MEN1 with regard to planning conception and, in unplanned pregnancy, how to follow NENs and pregnancy.

An individualized, multidisciplinary approach is to be developed involving gynecologists and neonatologists along with medical oncologists, endocrinologists, surgeons, and anesthesiologists. In addition, the patient's family is to be included when decisions for pregnancy are made, and a range of legal, ethical, religious, personal, and emotional factors are to be taken into account.

\section{Minimal Consensus Statement on F- and NF- DP-NENs MEN1 and Pregnancy}

Pregnancy does not change the diagnosis and treatment of gastrinoma and insulinoma. The symptoms of gastrinoma may be usefully controlled by the application of gastric antisecretory drugs, either prescribing H2-receptor antagonists or PPIs. H2-receptor antagonists are the preferred conservative treatment. PPIs should ideally be restricted to well-defined indications if no other treatment options are available and if the benefits outweigh the risks. The use of PPIs has shown an increased risk of congenital malformations. Uncontrolled hypoglycemia caused by insulinoma during pregnancy may cause fetal demise. Maintaining and monitoring reasonable levels of blood glucose through increased food intake, as frequently administered, may avoid complications. Diazoxide is the first line of medical treatment if conservative actions fail. Surgical treatment in localized insulinoma remains the only curative method. If conservative treatment fails, it is scheduled after 28 weeks of pregnancy or after birth. There is no clear evidence that functionality recurs in "surgically cured" F-DP-NENs. There are no arguments against pregnancy in asymptomatic, localized NENs $\leq 20 \mathrm{~mm}$ because there is no ev- idence that DP-NENs progress during pregnancy. Supporting teams of physicians should generally advise women with metastasizing disease requiring ongoing treatment against pregnancy. Liver-directed therapies as well as PRRT using radioactive drugs or chemotherapeutic agents and systemic therapies with targeted agents such as everolimus and sunitinib may be teratogenic and increase the risk of fetal demise.

\section{Acknowledgements}

The project was supported by the European Society of Endocrine Surgeons (ESES) and by the European Neuroendocrine Tumor Society (ENETS). The authors wish to thank Daniela Larwa and Karl Thomanek for their services in preparing the final version of this consensus statement. We are also grateful to Karl Thomanek for linguistic review and proofreading.

\section{Conflict of Interest Statement}

There is no conflict of interest to declare.

\section{Funding Sources}

This work was not financially supported.

\section{Author Contributions}

B.N. and A.S. developed the project idea underlying this consensus statement. All authors participating in the statement are members of the ESES and/or ENETS, which are responsible for the contents of the subtopic manuscripts. The authors drafted the individual manuscripts; their corresponding addresses are listed in the online suppl., Addendum 2. B.N. revised the overall consensus statement. B.N. and A.S. designed and prepared, and all authors approved the final version of the consensus statement. D.O. (ENETS), D.S.-C. (ESES), R.V.T., G.Th., G.Tr., and B.W. served as external reviewers.

References

1 Chandrasekharappa SC, Guru SC, Manickam P, Olufemi SE, Collins FS, Emmert-Buck MR, et al. Positional cloning of the gene for multiple endocrine neoplasia-type 1 . Science. 1997;276(5311):404-7.

2 Lemmens I, Van de Ven WJ, Kas K, Zhang CX, Giraud S, Wautot V, et al. Identification of the multiple endocrine neoplasia type 1 (MEN1) gene. The European Consortium on MEN1. Hum Mol Genet. 1997;6(7):1177-83.

3 Thakker RV. Multiple endocrine neoplasia type 1 (MEN1) and type 4 (MEN4). Mol Cell Endocrinol. 2014;386(1-2):2-15. 
4 Brandi ML, Gagel RF, Angeli A, Bilezikian JP, Beck-Peccoz P, Bordi C, et al. Guidelines for diagnosis and therapy of MEN type 1 and type 2. J Clin Endocrinol Metab. 2001;86(12): 5658-71.

5 Lemos MC, Thakker RV. Multiple endocrine neoplasia type 1 (MEN1): analysis of 1336 mutations reported in the first decade following identification of the gene. Hum Mutat. 2008;29(1):22-32.

6 Turner JJ, Christie PT, Pearce SH, Turnpenny PD, Thakker RV. Diagnostic challenges due to phenocopies: lessons from Multiple Endocrine Neoplasia type 1 (MEN1). Hum Mutat. 2010;31(1):E1089-101.

7 Newey PJ, Thakker RV. Role of multiple endocrine neoplasia type 1 mutational analysis in clinical practice. Endocr Pract. 2011; 17(Suppl 3):8-17.

8 Thakker RV, Newey PJ, Walls GV, Bilezikian J, Dralle H, Ebeling PR, et al. Clinical practice guidelines for multiple endocrine neoplasia type 1 (MEN1). J Clin Endocrinol Metab. 2012;97(9):2990-3011.

9 van Leeuwaarde RS, Dreijerink KM, Ausems MG, Beijers HJ, Dekkers OM, de Herder WW, et al. MEN1-dependent breast cancer: indication for early screening? Results from the Dutch MEN1 Study Group. J Clin Endocrinol Metab. 2017;102(6):2083-90.

10 Falconi M, Eriksson B, Kaltsas G, Bartsch DK, Capdevila J, Caplin M, et al. ENETS Consensus Guidelines update for the management of patients with functional pancreatic neuroendocrine tumors and non-functional pancreatic neuroendocrine tumors. Neuroendocrinology. 2016;103(2):153-71.

11 Yates CJ, Newey PJ, Thakker RV. Challenges and controversies in management of pancreatic neuroendocrine tumours in patients with MEN1. Lancet Diabetes Endocrinol. 2015; 3(11):895-905.

12 Jensen RT, Bodei L, Capdevila J, Couvelard A, Falconi M, Glasberg S, et al. The EMABP, participants EMAB: unmet needs in functional and nonfunctional pancreatic neuroendocrine neoplasms. Neuroendocrinology. 2019; 108:26-36.

13 Kunz PL, Reidy-Lagunes D, Anthony LB, Bertino EM, Brendtro K, Chan JA, et al. North American Neuroendocrine Tumor Society: consensus guidelines for the management and treatment of neuroendocrine tumors. Pancreas. 2013;42:557-77.

14 NCCN: Neuroendocrine and Adrenal Tumors Version 4. 2018. Clinical Practice Guidelines in Oncology, 2019. Available from: www.nccn.org.

15 Marini F, Giusti F, Brandi ML. Multiple endocrine neoplasia type 1: extensive analysis of a large database of Florentine patients. Orphanet J Rare Dis. 2018;13(1):205.

16 Trump D, Farren B, Wooding C, Pang JT, Besser GM, Buchanan KD, et al. Clinical studies of multiple endocrine neoplasia type 1 (MEN1). QJM. 1996;89:653-69.
17 Manoharan J, Albers MB, Bartsch DK. The future: diagnostic and imaging advances in MEN1 therapeutic approaches and management strategies. Endocr Relat Cancer. 2017; 24(10):T209-25.

18 Machens A, Schaaf L, Karges W, Frank-Raue K, Bartsch DK, Rothmund M, et al. Age-related penetrance of endocrine tumours in multiple endocrine neoplasia type 1 (MEN1): a multicentre study of 258 gene carriers. Clin Endocrinol. 2007;67(4):613-22.

19 Marx SJ, Vinik AI, Santen RJ, Floyd JC Jr., Mills JL, Green J 3rd. Multiple endocrine neoplasia type I: assessment of laboratory tests to screen for the gene in a large kindred. Medicine. 1986;65(4):226-41.

20 Bassett JH, Forbes SA, Pannett AA, Lloyd SE, Christie PT, Wooding C, et al. Characterization of mutations in patients with multiple endocrine neoplasia type 1 . Am J Hum Genet. 1998;62(2):232-44.

21 Goncalves TD, Toledo RA, Sekiya T, Matuguma SE, Maluf Filho F, Rocha MS, et al. Penetrance of functioning and nonfunctioning pancreatic neuroendocrine tumors in multiple endocrine neoplasia type 1 in the second decade of life. J Clin Endocrinol Metabol. 2014;99:E89-96.

22 Manoharan J, Raue F, Lopez CL, Albers MB, Bollmann C, Fendrich V, et al. Is routine screening of young asymptomatic MEN1 patients necessary? World J Surg. 2017;41(8): 2026-32.

23 Kann PH, Balakina E, Ivan D, Bartsch DK, Meyer S, Klose KJ, et al. Natural course of small, asymptomatic neuroendocrine pancreatic tumours in multiple endocrine neoplasia type 1: an endoscopic ultrasound imaging study. Endocr Relat Cancer. 2006;13(4): 1195-202.

24 Waldmann J, Fendrich V, Habbe N, Bartsch DK, Slater EP, Kann PH, et al. Screening of patients with multiple endocrine neoplasia type 1 (MEN-1): a critical analysis of its value. World J Surg. 2009;33(6):1208-18.

25 Kappelle WF, Valk GD, Leenders M, Moons LM, Bogte A, Siersema PD, et al. Growth rate of small pancreatic neuroendocrine tumors in multiple endocrine neoplasia type 1: results from an endoscopic ultrasound based cohort study. Endoscopy. 2017;49(1):27-34.

26 Anlauf M, Schlenger R, Perren A, Bauersfeld J, Koch CA, Dralle H, et al. Microadenomatosis of the endocrine pancreas in patients with and without the multiple endocrine neoplasia type 1 syndrome. Am J Surg Pathol. 2006; 30(5):560-74.

27 Triponez F, Dosseh D, Goudet P, Cougard P, Bauters C, Murat A, et al. Epidemiology data on 108 MEN 1 patients from the GTE with isolated nonfunctioning tumors of the pancreas. Ann Surg. 2006;243(2):265-72.

28 Jensen RT, Berna MJ, Bingham DB, Norton JA. Inherited pancreatic endocrine tumor syndromes: advances in molecular pathogenesis, diagnosis, management, and controversies. Cancer. 2008;113(7 Suppl):1807-43.
29 Fraenkel M, Kim MK, Faggiano A, Valk GD. Epidemiology of gastroenteropancreatic neuroendocrine tumours. Best Pract Res Clin Gastroenterol. 2012;26(6):691-703.

30 Triponez F, Goudet P, Dosseh D, Cougard P, Bauters C, Murat A, et al. Is surgery beneficial for MEN1 patients with small $(<$ or $=2 \mathrm{~cm})$, nonfunctioning pancreaticoduodenal endocrine tumor? An analysis of 65 patients from the GTE. World J Surg. 2006;30:654-62;

31 Ito $\mathrm{T}$, Igarashi $\mathrm{H}$, Uehara $\mathrm{H}$, Berna MJ, Jensen RT. Causes of death and prognostic factors in multiple endocrine neoplasia type 1: a prospective study: comparison of $106 \mathrm{MEN} 1 /$ Zollinger-Ellison syndrome patients with 1613 literature MEN1 patients with or without pancreatic endocrine tumors. Medicine. 2013;92(3):135-81.

32 Benson L, Ljunghall S, Akerström G, Oberg K. Hyperparathyroidism presenting as the first lesion in multiple endocrine neoplasia type 1. Am J Med. 1987;82(4):731-7.

33 Vasen HF, Lamers CB, Lips CJ. Screening for the multiple endocrine neoplasia syndrome type I. A study of 11 kindreds in The Netherlands. Arch Intern Med. 1989;149(12):271722.

34 Skogseid B, Larsson C, Lindgren PG, Kvanta E, Rastad J, Theodorsson E, et al. Clinical and genetic features of adrenocortical lesions in multiple endocrine neoplasia type 1 . J Clin Endocrinol Metab. 1992;75(1):76-81.

35 Burgess JR, Greenaway TM, Shepherd JJ. Expression of the MEN-1 gene in a large kindred with multiple endocrine neoplasia type 1 . J Intern Med. 1998;243(6):465-70.

36 Carty SE, Helm AK, Amico JA, Clarke MR, Foley TP, Watson CG, et al. The variable penetrance and spectrum of manifestations of multiple endocrine neoplasia type 1 . Surgery. 1998;124(6):1106-4; .

37 Levy-Bohbot N, Merle C, Goudet P, Delemer B, Calender A, Jolly D, et al. Prevalence, characteristics and prognosis of MEN 1-associated glucagonomas, VIPomas, and somatostatinomas: study from the GTE (Groupe des Tumeurs Endocrines) registry. Gastroenterol Clin Biol. 2004;28:1075-81.

38 Pieterman CR, Schreinemakers JM, Koppeschaar HP, Vriens MR, Rinkes IH, Zonnenberg BA, et al. Multiple endocrine neoplasia type 1 (MEN1): its manifestations and effect of genetic screening on clinical outcome. Clin Endocrinol. 2009;70(4):575-81.

39 Goudet P, Bonithon-Kopp C, Murat A, Ruszniewski P, Niccoli P, Ménégaux F, et al. Gender-related differences in MEN1 lesion occurrence and diagnosis: a cohort study of 734 cases from the Groupe d'etude des $\mathrm{Tu}$ meurs Endocrines. Eur J Endocrinol. 2011; 165(1):97-105

40 Pieterman CR, Vriens MR, Dreijerink KM, van der Luijt RB, Valk GD. Care for patients with multiple endocrine neoplasia type 1: the current evidence base. Fam Cancer. 2011; 10(1):157-71. 
41 Giudici F, Nesi G, Brandi ML, Tonelli F. Surgical management of insulinomas in multiple endocrine neoplasia type 1. Pancreas. 2012; 41(4):547-53.

42 Conemans EB, Nell S, Pieterman CRC, de Herder WW, Dekkers OM, Hermus AR, et al. Prognostic factors for survival of Men1 patients with duodenopancreatic tumors metastatic to the liver: results from the DMSG. Endocr Pract. 2017;23(6):641-8.

43 Giusti F, Cianferotti L, Boaretto F, Cetani F, Cioppi F, Colao A. Multiple endocrine neoplasia syndrome type 1: institution, management, and data analysis of a nationwide multicenter patient database. Endocrine. 2017; 58(2):349-59.

44 Albers MB, Manoharan J, Bollmann C, Chlosta MP, Holzer K, Bartsch DK. Results of duodenopancreatic reoperations in multiple endocrine neoplasia type 1. World J Surg. 2019; 43(2):552-8.

45 Wamsteker EJ, Gauger PG, Thompson NW, Scheiman JM. EUS detection of pancreatic endocrine tumors in asymptomatic patients with type 1 multiple endocrine neoplasia. Gastrointest Endosc. 2003;58(4):531-5.

46 Kouvaraki MA, Shapiro SE, Cote GJ, Lee JE, Yao JC, Waguespack SG, et al. Management of pancreatic endocrine tumors in multiple endocrine neoplasia type 1 . World J Surg. 2006;30(5):643-53.

47 Thomas-Marques L, Murat A, Delemer B, Penfornis A, Cardot-Bauters C, Baudin E, et al. Prospective endoscopic ultrasonographic evaluation of the frequency of nonfunctioning pancreaticoduodenal endocrine tumors in patients with multiple endocrine neoplasia type 1. Am J Gastroenterol. 2006;101:266-73.

48 Vierimaa O, Ebeling TM, Kytölä S, Bloigu R, Eloranta E, Salmi J, et al. Multiple endocrine neoplasia type 1 in Northern Finland; clinical features and genotype phenotype correlation. Eur J Endocrinol. 2007;157(3):285-94.

49 Lopez CL, Waldmann J, Fendrich V, Langer P, Kann PH, Bartsch DK. Long-term results of surgery for pancreatic neuroendocrine neoplasms in patients with MEN1. Langenbecks Arch Surg. 2011;396(8):1187-96.

50 Sakurai A, Yamazaki M, Suzuki S, Fukushima $\mathrm{T}$, Imai T, Kikumori T, et al. Clinical features of insulinoma in patients with multiple endocrine neoplasia type 1: analysis of the database of the MEN Consortium of Japan. Endocr J. 2012;59(10):859-66.

51 Goudet P, Dalac A, Le Bras M, Cardot-Bauters C, Niccoli P, Levy-Bohbot N, et al. MEN1 disease occurring before 21 years old: a 160-patient cohort study from the Groupe d'etude des Tumeurs Endocrines. J Clin Endocrinol Metab. 2015;100:1568-77.

52 Manoharan J, Bollmann C, Kann PH, Di Fazio P, Bartsch DK, Albers MB. Gender differences in multiple endocrine neoplasia type 1: implications for screening? Visc Med. 2020; 36(1):3-9.
53 de Laat JM, Pieterman CR, Weijmans M, Hermus AR, Dekkers OM, de Herder WW, et al. Low accuracy of tumor markers for diagnosing pancreatic neuroendocrine tumors in multiple endocrine neoplasia type 1 patients. J Clin Endocrinol Metab. 2013;98(10):414351.

54 Ito T, Jensen RT. Imaging in multiple endocrine neoplasia type 1: recent studies show enhanced sensitivities but increased controversies. Int J Endocr Oncol. 2016;3(1):53-66.

55 Jensen RT, Cadiot G, Brandi ML, de Herder WW, Kaltsas G, Komminoth P, et al. ENETS Consensus guidelines for the management of patients with digestive neuroendocrine neoplasms: functional pancreatic endocrine tumor syndromes. Neuroendocrinology. 2012; 95(2):98-119.

56 Qiu W, Christakis I, Silva A, Bassett RL Jr, Cao L, Meng QH, et al. Utility of chromogranin A, pancreatic polypeptide, glucagon and gastrin in the diagnosis and follow-up of pancreatic neuroendocrine tumours in multiple endocrine neoplasia type 1 patients. Clin Endocrinol. 2016;85(3):400-7.

57 Goswami S, Peipert BJ, Helenowski I, Yount $\mathrm{SE}$, Sturgeon C. Disease and treatment factors associated with lower quality of life scores in adults with multiple endocrine neoplasia type I. Surgery. 2017;162(6):1270-7.

58 Stromsvik N, Nordin K, Berglund G, Engebretsen LF, Hansson MG, Gjengedal E. Living with multiple endocrine neoplasia type 1: decent care-insufficient medical and genetic information: a qualitative study of MEN 1 patients in a Swedish hospital. J Genet Couns. 2007;16:105-17.

59 Ito T, Cadiot G, Jensen RT. Diagnosis of Zollinger-Ellison syndrome: increasingly difficult. World J Gastroenterol. 2012;18(39): 5495-503.

60 Ito T, Igarashi H, Jensen RT. Zollinger-Ellison syndrome: recent advances and controversies. Curr Opin Gastroenterol. 2013;29(6): 650-61.

61 Metz DC, Cadiot G, Poitras P, Ito T, Jensen RT. Diagnosis of Zollinger-Ellison syndrome in the era of PPIs, faulty gastrin assays, sensitive imaging and limited access to acid secretory testing. Int J Endocr Oncol. 2017;4(4): $167-85$.

62 Oh DS, Wang HS, Ohning GV, Pisegna JR. Validation of a new endoscopic technique to assess acid output in Zollinger-Ellison syndrome. Clin Gastroenterol Hepatol. 2006; 4(12):1467-73.

63 Jensen RT, Niederle B, Mitry E, Ramage JK, Steinmuller T, Lewington V; European Neuroendocrine Tumor S, et al. Gastrinoma (duodenal and pancreatic). Neuroendocrinology. 2006;84(3):173-82.

64 Poitras P, Gingras MH, Rehfeld JF. The Zollinger-Ellison syndrome: dangers and consequences of interrupting antisecretory treatment. Clin Gastroenterol Hepatol. 2012; 10(2):199-202.
65 Poitras P, Gingras MH, Rehfeld JF. Secretin stimulation test for gastrin release in Zollinger-Ellison syndrome: to do or not to do? Pancreas. 2013;42(6):903-4.

66 Rehfeld JF, Bardram L, Hilsted L, Goetze JP. An evaluation of chromogranin A versus gastrin and progastrin in gastrinoma diagnosis and control. Biomark Med. 2014;8(4):571-80.

67 Rehfeld JF, Bardram L, Hilsted L, Poitras P, Goetze JP. Pitfalls in diagnostic gastrin measurements. Clin Chem. 2012;58(5):831-6.

68 Rehfeld JF, Gingras MH, Bardram L, Hilsted L, Goetze JP, Poitras P. The Zollinger-Ellison syndrome and mismeasurement of gastrin. Gastroenterology. 2011;140(5):1444-53.

69 Shah P, Guo T, Moore DD, Ghose R. Role of constitutive androstane receptor in Toll-like receptor-mediated regulation of gene expression of hepatic drug-metabolizing enzymes and transporters. Drug Metab Dispos. 2014; 42(1):172-81.

70 Shibata C, Kakyo M, Kinouchi M, Tanaka N, Miura K, Naitoh T, et al. Criteria for the glucagon provocative test in the diagnosis of gastrinoma. Surg Today. 2013;43(11):1281-5.

71 Ito T, Igarashi H, Jensen RT. Pancreatic neuroendocrine tumors: clinical features, diagnosis and medical treatment: advances. Best Pract Res Clin Gastroenterol. 2012;26(6): 737-53.

72 Norton JA, Krampitz G, Jensen RT. Multiple endocrine neoplasia: genetics and clinical management. Surg Oncol Clin N Am. 2015; 24(4):795-832.

73 Berna MJ, Annibale B, Marignani M, Luong TV, Corleto V, Pace A, et al. A prospective study of gastric carcinoids and enterochromaffin-like cell changes in multiple endocrine neoplasia type 1 and Zollinger-Ellison syndrome: identification of risk factors. J Clin Endocrinol Metab. 2008;93(5):1582-91.

74 Frucht H, Howard JM, Slaff JI, Wank SA, McCarthy DM, Maton PN, et al. Secretin and calcium provocative tests in the Zollinger-Ellison syndrome. A prospective study. Ann Intern Med. 1989;111(9):713-22.

75 Roy PK, Venzon DJ, Shojamanesh H, AbouSaif A, Peghini P, Doppman JL, et al. ZollingerEllison syndrome. Clinical presentation in 261 patients. Medicine. 2000;79(6):379-411.

76 Cryer PE, Axelrod L, Grossman AB, Heller SR, Montori VM, Seaquist ER, et al. Evaluation and management of adult hypoglycemic disorders: an Endocrine Society Clinical Practice Guideline. J Clin Endocrinol Metab. 2009; 94(3):709-28.

77 Metz DC, Jensen RT. Gastrointestinal neuroendocrine tumors: pancreatic endocrine tumors. Gastroenterology. 2008;135(5):146992.

78 Kim GY, Kim S, Ong RKS, Shawa H. Simultaneous glucagon and vasoactive intestinal peptide producing pancreatic neuroendocrine tumors in a patient with multiple endocrine neoplasia type 1: a case report and literature review. Pancreas. 2018;47:e1-2. 
79 Thakker RV, Newey PJ, Walls GV, Bilezikian J, Dralle H, Ebeling PR, et al. Clinical practice guidelines for multiple endocrine neoplasia type 1 (MEN1). J Clin Endocrinol Metab. 2012;97(9):2990-3011.

80 Casey RT, Saunders D, Challis BG, Pitfield D, Cheow H, Shaw A, et al. Radiological surveillance in multiple endocrine neoplasia type 1: a double-edged sword? Endocr Connect. 2017;6(3):151-8.

81 Albers MB, Librizzi D, Lopez CL, Manoharan J, Apitzsch JC, Slater EP, et al. Limited value of Ga-68-DOTATOC-PET-CT in routine screening of patients with multiple endocrine neoplasia type 1. World J Surg. 2017;41(6): 1521-7.

82 Rockall AG, Reznek RH. Imaging of neuroendocrine tumours (CT/MR/US). Best Pract Res Clin Endocrinol Metab. 2007;21(1):43-68.

83 Noone TC, Hosey J, Firat Z, Semelka RC. Imaging and localization of islet-cell tumours of the pancreas on CT and MRI. Best Pract Res Clin Endocrinol Metab. 2005;19(2):195-211.

84 Reubi JC. Peptide receptors as molecular targets for cancer diagnosis and therapy. Endocr Rev. 2003;24(4):389-427.

85 Haug A, Auernhammer CJ, Wängler B, Tiling R, Schmidt G, Göke B, et al. Intraindividual comparison of 68Ga-DOTA-TATE and 18FDOPA PET in patients with well-differentiated metastatic neuroendocrine tumours. Eur J Nucl Med Mol Imaging. 2009;36(5):765-70.

86 Koukouraki S, Strauss LG, Georgoulias V, Eisenhut M, Haberkorn U, Dimitrakopoulou-Strauss A. Comparison of the pharmacokinetics of $68 \mathrm{Ga}-\mathrm{DOTATOC}$ and [18F]FDG in patients with metastatic neuroendocrine tumours scheduled for 90Y-DOTATOC therapy. Eur J Nucl Med Mol Imaging. 2006; 33(10):1115-22.

87 Kayani I, Bomanji JB, Groves A, Conway G, Gacinovic S, Win T, et al. Functional imaging of neuroendocrine tumors with combined $\mathrm{PET} / \mathrm{CT}$ using 68Ga-DOTATATE (DOTADPhe1,Tyr3-octreotate) and 18F-FDG. Cancer. 2008;112(11):2447-55.

88 Falconi M, Bartsch DK, Eriksson B, Klöppel G, Lopes JM, O'Connor JM, et al. ENETS Consensus Guidelines for the management of patients with digestive neuroendocrine neoplasms of the digestive system: well-differentiated pancreatic non-functioning tumors. Neuroendocrinology. 2012;95(2):120-34.

89 Hofman MS, Kong G, Neels OC, Eu P, Hong E, Hicks RJ. High management impact of Ga68 DOTATATE (GaTate) PET/CT for imaging neuroendocrine and other somatostatin expressing tumours. J Med Imaging Radiat Oncol. 2012;56(1):40-7.

90 Frilling A, Sotiropoulos GC, Radtke A, Malago M, Bockisch A, Kuehl H, et al. The impact of $68 \mathrm{Ga}$-DOTATOC positron emission tomography/computed tomography on the multimodal management of patients with neuroendocrine tumors. Ann Surg. 2010; 252(5):850-6.
91 Ruf J, Heuck F, Schiefer J, Denecke T, Elgeti F, Pascher A, et al. Impact of Multiphase 68Ga-DOTATOC-PET/CT on therapy management in patients with neuroendocrine tumors. Neuroendocrinology. 2010; 91(1):101-9.

92 van Treijen MJC, van Beek D-J, van Leeuwaarde RS, Vriens MR, Valk GD. Diagnosing nonfunctional pancreatic NETs in MEN1: the evidence base. J Endocr Soc. 2018;2(9):1067-88.

93 Antwi K, Nicolas G, Fani M, Heye T, Pattou F, Grossman A, et al. 68Ga-exendin-4 PET/ CT detects insulinomas in patients with endogenous hyperinsulinemic hypoglycemia in MEN-1. J Clin Endocrinol Metab. 2019 Dec 1;104(12):5843-52.

94 Doppman JL, Miller DL, Chang R, Shawker $\mathrm{TH}$, Gorden P, Norton JA. Insulinomas: localization with selective intraarterial injection of calcium. Radiology. 1991;178(1): $237-41$.

95 Imamura M, Komoto I, Ota S, Hiratsuka T, Kosugi S, Doi R, et al. Biochemically curative surgery for gastrinoma in multiple endocrine neoplasia type 1 patients. World J Gastroenterol. 2011;17(10):1343-53.

96 Polenta V, Slater EP, Kann PH, Albers MB, Manoharan J, Ramaswamy A, Preoperative imaging overestimates the tumor size in pancreatic neuroendocrine neoplasms associated with multiple endocrine neoplasia type 1. World J Surg 2018;42(5):1440-7.

97 et al P, Hennings J, Akerstrom G, Akerström B. Endoscopic ultrasonography for evaluation of pancreatic tumours in multiple endocrine neoplasia type 1. Br J Surg. 2005; 92(12):1508-12.

98 Langer P, Kann PH, Fendrich V, Richter G, Diehl S, Rothmund M, et al. Prospective evaluation of imaging procedures for the detection of pancreaticoduodenal endocrine tumors in patients with multiple endocrine neoplasia type 1. World J Surg. 2004;28(12): 1317-22.

99 Lewis MA, Thompson GB, Young WF Jr. Preoperative assessment of the pancreas in multiple endocrine neoplasia type 1 . World J Surg. 2012;36(6):1375-81.

100 van Asselt SJ, Brouwers AH, van Dullemen HM, van der Jagt EJ, Bongaerts AH, Kema IP, et al. EUS is superior for detection of pancreatic lesions compared with standard imaging in patients with multiple endocrine neoplasia type 1. Gastrointest Endosc. 2015; 81(1):159-e2.

101 Triponez F, Dosseh D, Goudet P, Cougard $\mathrm{P}$, Bauters C, Murat A, et al. Epidemiology data on 108 MEN 1 patients from the GTE with isolated nonfunctioning tumors of the pancreas. Ann Surg. 2006;243(2):265-72.

102 Kouvaraki MA, Shapiro SE, Cote GJ, Lee JE, Yao JC, Waguespack SG, et al. Management of pancreatic endocrine tumors in multiple endocrine neoplasia type 1 . World J Surg. 2006;30(5):643-53.
103 Akerstrom G, Stalberg P, Hellman P. Surgical management of pancreatico-duodenal tumors in multiple endocrine neoplasia syndrome type 1. Clinics. 2012;67(Suppl 1): 173-8.

104 Bartsch DK, Fendrich V, Langer P, Celik I, Kann PH, Rothmund M. Outcome of duodenopancreatic resections in patients with multiple endocrine neoplasia type 1 . Ann Surg. 2005;242(6):757-6;

105 Hanazaki K, Sakurai A, Munekage M, Ichikawa K, Namikawa T, Okabayashi T, et al. Surgery for a gastroenteropancreatic neuroendocrine tumor (GEPNET) in multiple endocrine neoplasia type 1 . Surg Today. 2013;43(3):229-36

106 Sadowski SM, Triponez F. Management of pancreatic neuroendocrine tumors in patients with MEN 1. Gland Surg. 2015;4(1): 63-8.

107 Sadowski SM, Cadiot G, Dansin E, Goudet $\mathrm{P}$, Triponez F. The future: surgical advances in MEN1 therapeutic approaches and management strategies. Endocr Relat Cancer. 2017;24(10):T243-260.

108 Triponez F, Sadowski SM, Pattou F, CardotBauters C, Mirallie E, Le Bras M, et al. Longterm follow-up of MEN1 patients who do not have initial surgery for small $</=2 \mathrm{~cm}$ nonfunctioning pancreatic neuroendocrine tumors, an AFCE and GTE study: association Francophone de Chirurgie Endocrinienne \& Groupe d'Etude des Tumeurs Endocrines. Ann Surg. 2018 Jul;268(1):158-64.

109 Triponez F, Sadowski SM, Pattou F, CardotBauters C, Mirallie E, Le Bras M, et al. Longterm follow-up of MEN1 patients who do not have initial surgery for small $</=2 \mathrm{~cm}$ nonfunctioning pancreatic neuroendocrine tumors, an AFCE and GTE study: association Francophone de Chirurgie Endocrinienne \& Groupe d'Etude des Tumeurs Endocrines. Ann Surg. 2018;268:158-64.

110 Vinault S, Mariet AS, Le Bras M, Mirallie E, Cardot-Bauters C, Pattou F, et al. Metastatic potential and survival of duodenal and pancreatic tumors in multiple endocrine neoplasia type 1: a GTE and AFCE Cohort Study (Groupe d'etude des Tumeurs Endocrines and Association Francophone de Chirurgie Endocrinienne). Ann Surg. 2018

111 Norton JA, Fraker DL, Alexander HR, Gibril F, Liewehr DJ, Venzon DJ, et al. Surgery increases survival in patients with gastrinoma. Ann Surg. 2006;244(3):410-9.

112 Norton JA. Surgical treatment and prognosis of gastrinoma. Best Pract Res Clin Gastroenterol. 2005;19(5):799-805.

113 Bartsch DK, Langer P, Wild A, Schilling T, Celik I, Rothmund M, et al. Pancreaticoduodenal endocrine tumors in multiple endocrine neoplasia type 1: surgery or surveillance? Surgery. 2000;128(6):958-66. 
114 Lopez CL, Falconi M, Waldmann J, Boninsegna L, Fendrich V, Goretzki PK, et al. Partial pancreaticoduodenectomy can provide cure for duodenal gastrinoma associated with multiple endocrine neoplasia type 1 . Ann Surg. 2013;257(2):308-14

115 Selberherr A, Koperek O, Riss P, Scheuba C, Niederle MB, Kaderli R, Intertumor heterogeneity in 60 pancreatic neuroendocrine tumors associated with multiple endocrine neoplasia type 1. Orphanet J Rare Dis. 2019; 14(1):54.

116 de Wilde RF, Heaphy CM, Maitra A, Meeker AK, Edil BH, Wolfgang CL, et al. Loss of ATRX or DAXX expression and concomitant acquisition of the alternative lengthening of telomeres phenotype are late events in a small subset of MEN-1 syndrome pancreatic neuroendocrine tumors. Mod Pathol. 2012;25:1033-9.

117 Sadowski SM, Pieterman CRC, Perrier ND, Triponez F, Valk GD. Prognostic factors for the outcome of nonfunctioning pancreatic neuroendocrine tumors in MEN1: a systematic review of literature. Endocr Relat Cancer. 2020;27(6):R145-61.

118 Klimstra DSKG, La Rosa S, Rindi G. Classification of neuroendocrine neoplasms of the digestive system. Lyon, France: International Agency for Research on Cancer; 2019.

119 Thevenon J, Bourredjem A, Faivre L, Cardot-Bauters C, Calender A, Murat A, et al. Higher risk of death among MEN1 patients with mutations in the JunD interacting domain: a Groupe d'etude des Tumeurs Endocrines (GTE) cohort study. Hum Mol Genet. 2013;22(10):1940-8.

120 Bartsch DK, Slater EP, Albers M, Knoop R, Chaloupka B, Lopez CL, et al. Higher risk of aggressive pancreatic neuroendocrine tumors in MEN1 patients with MEN1 mutations affecting the CHES1 interacting MENIN domain. J Clin Endocrinol Metab. 2014;99(11):E2387-91.

121 Christakis I, Qiu W, Hyde SM, Cote GJ, Grubbs EG, Perrier ND, et al. Genotypephenotype pancreatic neuroendocrine tumor relationship in multiple endocrine neoplasia type 1 patients: a 23 -year experience at a single institution. Surgery. 2018;163:2127.

122 Hasani-Ranjbar S, Amoli MM, EbrahimHabibi A, Gozashti MH, Khalili N, Sayyahpour FA, et al. A new frameshift MEN1 gene mutation associated with familial malignant insulinomas. Fam Cancer. 2011;10(2):3438.

123 Raef H, Zou M, Baitei EY, Al-Rijjal RA, Kaya $\mathrm{N}$, Al-Hamed $\mathrm{M}$, et al. A novel deletion of the MEN1 gene in a large family of multiple endocrine neoplasia type 1 (MEN1) with aggressive phenotype. Clin Endocrinol. 2011; 75(6):791-800.
124 Anlauf M, Garbrecht N, Henopp T, Schmitt A, Schlenger R, Raffel A, et al. Sporadic versus hereditary gastrinomas of the duodenum and pancreas: distinct clinico-pathological and epidemiological features. World J Gastroenterol. 2006;12(34):5440-6.

125 Norton JA, Alexander HR, Fraker DL, Venzon DJ, Gibril F, Jensen RT. Comparison of surgical results in patients with advanced and limited disease with multiple endocrine neoplasia type 1 and Zollinger-Ellison syndrome. Ann Surg. 2001;234(4):495-6;

126 Pipeleers-Marichal M, Somers G, Willems G, Foulis A, Imrie C, Bishop AE, et al. Gastrinomas in the duodenums of patients with multiple endocrine neoplasia type 1 and the Zollinger-Ellison syndrome. N Engl J Med. 1990;322(11):723-7.

127 Anlauf M, Enosawa T, Henopp T, Schmitt A, Gimm O, Brauckhoff $M$, et al. Primary lymph node gastrinoma or occult duodenal microgastrinoma with lymph node metastases in a MEN1 patient: the need for a systematic search for the primary tumor. Am J Surg Pathol. 2008;32(7):1101-5.

128 Thompson NW. Current concepts in the surgical management of multiple endocrine neoplasia type 1 pancreatic-duodenal disease. Results in the treatment of 40 patients with Zollinger-Ellison syndrome, hypoglycaemia or both. J Intern Med. 1998;243(6): 495-500.

129 Cadiot G, Vuagnat A, Doukhan I, Murat A, Bonnaud G, Delemer B, et al. Prognostic factors in patients with Zollinger-Ellison syndrome and multiple endocrine neoplasia type 1. Groupe d'Etude des Neoplasies Endocriniennes Multiples (GENEM and groupe de Recherche et d'Etude du Syndrome de Zollinger-Ellison (GRESZE). Gastroenterology. 1999;116:286-93.

130 Weber HC, Venzon DJ, Lin JT, Fishbein VA, Orbuch M, Strader DB, et al. Determinants of metastatic rate and survival in patients with Zollinger-Ellison syndrome: a prospective long-term study. Gastroenterology. 1995;108(6):1637-49.

131 Yu F, Venzon DJ, Serrano J, Goebel SU, Doppman JL, Gibril F, et al. Prospective study of the clinical course, prognostic factors, causes of death, and survival in patients with long-standing Zollinger-Ellison syndrome. J Clin Oncol. 1999;17(2):615-30.

132 Norton JA, Jensen RT. Resolved and unresolved controversies in the surgical management of patients with Zollinger-Ellison syndrome. Ann Surg. 2004;240(5):757-73.

133 Gibril F, Venzon DJ, Ojeaburu JV, Bashir S, Jensen RT. Prospective study of the natural history of gastrinoma in patients with MEN1: definition of an aggressive and a nonaggressive form. J Clin Endocrinol Metab. 2001;86(11):5282-93.
134 Norton JA, Cornelius MJ, Doppman JL, Maton PN, Gardner JD, Jensen RT. Effect of parathyroidectomy in patients with hyperparathyroidism, Zollinger-Ellison syndrome, and multiple endocrine neoplasia type I: a prospective study. Surgery. 1987; 102(6):958-66.

135 Lee MJ, Jung CH, Jang JE, Hwang JY, Park DH, Park TS, et al. Successful endoscopic ultrasound-guided ethanol ablation of multiple insulinomas accompanied with multiple endocrine neoplasia type 1. Intern Med J. 2013;43(8):948-50.

136 Tonelli F. How to follow up and when to operate asymptomatic pancreatic neuroendocrine tumors in multiple endocrine neoplasia type 1? J Clin Gastroenterol. 2014;48(5): 387-9.

137 Tonelli F, Fratini G, Falchetti A, Nesi G, Brandi ML. Surgery for gastroenteropancreatic tumours in multiple endocrine neoplasia type 1: review and personal experience. J Intern Med. 2005;257(1):38-49.

138 Bartsch DK, Albers M, Knoop R, Kann PH Fendrich V, Waldmann J. Enucleation and limited pancreatic resection provide longterm cure for insulinoma in multiple endocrine neoplasia type 1 . Neuroendocrinology. 2013;98(4):290-8.

139 Harper S, Harrison B. First surgery for pancreatic neuroendocrine tumours in a patient with MEN1: enucleation versus diseasemodifying surgery. Clin Endocrinol. 2015; 83(5):618-21.

140 Norton JA, Krampitz G, Zemek A, Longacre $\mathrm{T}$, Jensen RT. Better survival but changing causes of death in patients with multiple endocrine neoplasia type 1. Ann Surg. 2015; 261(6):e147.

141 Hausman MS Jr, Thompson NW, Gauger PG, Doherty GM. The surgical management of MEN-1 pancreatoduodenal neuroendocrine disease. Surgery. 2004;136(6):1205-11.

142 Gauger PG, Doherty GM, Broome JT, Miller BS, Thompson NW. Completion pancreatectomy and duodenectomy for recurrent MEN-1 pancreaticoduodenal endocrine neoplasms. Surgery. 2009;146(4):801-8; .

143 Ratnayake CBB, Loveday BP, Windsor JA, Lawrence B, Pandanaboyana S. Patient characteristics and clinical outcomes following initial surgical intervention for MEN1 associated pancreatic neuroendocrine tumours: a systematic review and exploratory metaanalysis of the literature. Pancreatology. 2019;19(3):462-71.

144 Fernandez-Cruz L, Blanco L, Cosa R, Rendon $H$. Is laparoscopic resection adequate in patients with neuroendocrine pancreatic tumors? World J Surg. 2008;32:904-17.

145 Fernandez-Cruz L, Molina V, Vallejos R, Jimenez Chavarria E, Lopez-Boado MA, Ferrer J. Outcome after laparoscopic enucleation for non-functional neuroendocrine pancreatic tumours. HPB. 2012;14:171-6. 
146 Haugvik SP, Marangos IP, Røsok BI, Pomianowska E, Gladhaug IP, Mathisen O, et al. Long-term outcome of laparoscopic surgery for pancreatic neuroendocrine tumors. World J Surg. 2013;37(3):582-90.

147 Lopez CL, Albers MB, Bollmann C, Manoharan J, Waldmann J, Fendrich V, et al. Minimally invasive versus open pancreatic surgery in patients with multiple endocrine neoplasia type 1. World J Surg. 2016;40(7): 1729-36.

148 Blanc P, Porcheron J, Pages A, Breton C, Mosnier JF, Balique JG. [Laparoscopic excision of a duodenal neuroendocrine tumor]. Ann Chir. 2000;125(2):176-8.

149 Kim SC, Song KB, Jung YS, Kim YH, Park $\mathrm{DH}$, Lee SS, et al. Short-term clinical outcomes for 100 consecutive cases of laparoscopic pylorus-preserving pancreatoduodenectomy: improvement with surgical experience. Surg Endosc. 2013;27(1):95-103.

150 Zureikat AH, Nguyen KT, Bartlett DL, Zeh HJ, Moser AJ. Robotic-assisted major pancreatic resection and reconstruction. Arch Surg. 2011;146(3):256-61.

151 Pavel M, Baudin E, Couvelard A, Krenning E, Öberg K, Steinmüller T, et al. ENETS Consensus Guidelines for the management of patients with liver and other distant metastases from neuroendocrine neoplasms of foregut, midgut, hindgut, and unknown primary. Neuroendocrinology. 2012;95(2): 157-76.

152 Dy BM, Que FG, Thompson GB, Young WF, Rowse P, Strajina V, et al. Metastasectomy of neuroendocrine tumors in patients with multiple endocrine neoplasia type 1 . Am J Surg. 2014;208(6):1047-3; discussion 1052-3.

153 Chiloiro S, Lanza F, Bianchi A, Schinzari G, Brizi MG, Giampietro A. Pancreatic neuroendocrine tumors in MEN1 disease: a mono-centric longitudinal and prognostic study. Endocrine. 2018;60(2):362-7.

154 Bertani E, Fazio N, Botteri E, Chiappa A, Falconi M, Grana C, et al. Resection of the primary pancreatic neuroendocrine tumor in patients with unresectable liver metastases: possible indications for a multimodal approach. Surgery. 2014;155(4):607-14.

155 Capurso G, Bettini R, Rinzivillo M, Boninsegna L, Delle Fave G, Falconi M. Role of resection of the primary pancreatic neuroendocrine tumour only in patients with unresectable metastatic liver disease: a systematic review. Neuroendocrinology. 2011;93(4): 223-9.

156 Frilling A, Modlin IM, Kidd M, Russell C, Breitenstein S, Salem R, et al. Recommendations for management of patients with neuroendocrine liver metastases. Lancet Oncol. 2014;15(1):e8-21.

157 Partelli S, Cirocchi R, Rancoita PMV, Muffatti F, Andreasi V, Crippa S, Systematic review and meta-analysis on the role of palliative primary resection for pancreatic neuroendocrine neoplasm with liver metastases. HPB 2018;20(3):197-203.
158 Scigliano S, Lebtahi R, Maire F, Stievenart JL, Kianmanesh R, Sauvanet A, et al. Clinical and imaging follow-up after exhaustive liver resection of endocrine metastases: a 15-year monocentric experience. Endocr Relat Cancer. 2009;16(3):977-90.

159 Chamberlain RS, Canes D, Brown KT, Saltz L, Jarnagin W, Fong Y, et al. Hepatic neuroendocrine metastases: does intervention alter outcomes? J Am Coll Surg. 2000;190(4): 432-45.

160 Hori T, Takaori K, Uemoto S. Pancreatic neuroendocrine tumor accompanied with multiple liver metastases. World J Hepatol. 2014;6(8):596-600.

161 Modlin IM, Oberg K, Chung DC, Jensen RT, de Herder WW, Thakker RV, et al. Gastroenteropancreatic neuroendocrine tumours. Lancet Oncol. 2008;9(1):61-72.

162 Pieterman CRC, Sadowski SM, Maxwell JE, Katz MHG, Lines KE, Heaphy CM, et al. MEN1-related PanNETs: identifying unmet clinical needs and future directives. Endocr Relat Cancer. 2020;27(8).

163 de Laat JM, van der Luijt RB, Pieterman CR, Oostveen MP, Hermus AR, Dekkers OM, et al. MEN1 redefined, a clinical comparison of mutation-positive and mutation-negative patients. BMC Med. 2016;14(1):182.

164 Sakurai A, Suzuki S, Kosugi S, Okamoto T, Uchino S, Miya A, et al. Multiple endocrine neoplasia type 1 in Japan: establishment and analysis of a multicentre database. Clin Endocrinol. 2012;76(4):533-9.

165 Conemans EB, Brosens LAA, Raicu-Ionita GM, Pieterman CRC, de Herder WW, Dekkers OM, et al. Prognostic value of WHO grade in pancreatic neuro-endocrine tumors in multiple endocrine neoplasia type 1: results from the DutchMEN1 study group. Pancreatology. 2017;17(5):766-72.

166 Ito $\mathrm{T}$, Igarashi $\mathrm{H}$, Uehara $\mathrm{H}$, Jensen RT. Pharmacotherapy of Zollinger-Ellison syndrome. Expert Opin Pharmacother. 2013; 14(3):307-21.

167 Jensen RT, Norton JA. Treatment of pancreatic neuroendocrine tumors in multiple endocrine neoplasia type 1: some clarity but continued controversy. Pancreas. 2017; 46(5):589-94.

168 Gibril F, Schumann M, Pace A, Jensen RT. Multiple endocrine neoplasia type 1 and Zollinger-Ellison syndrome: a prospective study of 107 cases and comparison with 1009 cases from the literature. Medicine. 2004; 83(1):43-83.

169 Roy PK, Venzon DJ, Feigenbaum KM, Koviack PD, Bashir S, Ojeaburu JV, et al. Gastric secretion in Zollinger-Ellison syndrome. Correlation with clinical expression, tumor extent and role in diagnosis-a prospective NIH study of 235 patients and a review of 984 cases in the literature. Medicine. 2001; 80:189-222.
170 Jensen R, Gardner JD. Gastrinoma. New York: Raven Press Publishing Co.; 1993.

171 Ellison EH, Wilson SD. The Zollinger-Ellison syndrome: re-appraisal and evaluation of 260 registered cases. Ann Surg. 1964;160: 512-30.

172 Jensen RT, Gardner JD, Raufman JP, Pandol SJ, Doppman JL, Collen MJ. Zollinger-Ellison syndrome: current concepts and management. Ann Intern Med. 1983;98(1):5975 .

173 O'Riordain DS, O'Brien T, van Heerden JA, Service FJ, Grant CS. Surgical management of insulinoma associated with multiple endocrine neoplasia type I. World J Surg. 1994; 18(4):488-4; discussion 493-484.

174 Sheppard BC, Norton JA, Doppman JL, Maton PN, Gardner JD, Jensen RT. Management of islet cell tumors in patients with multiple endocrine neoplasia: a prospective study. Surgery. 1989;106(6):1108-8; discussion 1117-8.

175 Tonelli F, Giudici F, Nesi G, Batignani G, Brandi ML. Operation for insulinomas in multiple endocrine neoplasia type 1: when pancreatoduodenectomy is appropriate. Surgery. 2017;161(3):727-34.

176 Metz DC, Sostek MB, Ruszniewski P, Forsmark CE, Monyak J, Pisegna JR. Effects of esomeprazole on acid output in patients with Zollinger-Ellison syndrome or idiopathic gastric acid hypersecretion. Am J Gastroenterol. 2007;102(12):2648-54.

177 Morocutti A, Merrouche M, Bjaaland T, Humphries T, Mignon M. An open-label study of rabeprazole in patients with Zollinger-Ellison syndrome or idiopathic gastric acid hypersecretion. Aliment Pharmacol Ther. 2006;24(10):1439-44.

178 Yang YX, Metz DC. Safety of proton pump inhibitor exposure. Gastroenterology. 2010 139(4):1115-27.

179 Modlin IM, Pavel M, Kidd M, Gustafsson BI. Review article: somatostatin analogues in the treatment of gastroenteropancreatic neuroendocrine (carcinoid) tumours. Aliment Pharmacol Ther. 2010;31(2):169-88.

180 Ito T, Lee L, Jensen RT. Treatment of symptomatic neuroendocrine tumor syndromes: recent advances and controversies. Expert Opin Pharmacother. 2016;17(16):2191-205.

181 Goode PN, Farndon JR, Anderson J, Johnston ID, Morte JA. Diazoxide in the management of patients with insulinoma. World J Surg. 1986;10(4):586-92.

182 Del Prete M, Marotta V, Ramundo V, Marciello F, Di Sarno A, Esposito R, Impact of cinacalcet hydrochloride in clinical management of primary hyperparathyroidism in multiple endocrine neoplasia type 1. Minerva Endocrinol. 2013;38(4):389-94.

183 et al F, Cianferotti L, Gronchi G, Cioppi F, Masi L, Faggiano A, et al. Cinacalcet therapy in patients affected by primary hyperparathyroidism associated to Multiple Endocrine Neoplasia Syndrome type 1 (MEN1). Endocrine. 2016;52(3):495-506. 
184 Partelli S, Bartsch DK, Capdevila J, Chen J, Knigge U, Niederle B, et al. Antibes consensus conference p: ENETS Consensus Guidelines for standard of care in neuroendocrine tumours: surgery for small intestinal and pancreatic neuroendocrine tumours. Neuroendocrinology. 2017;105:255-65.

185 Cioppi F, Cianferotti L, Masi L, Giusti F, Brandi ML. The LARO-MEN1 study: a longitudinal clinical experience with octreotide long-acting release in patients with multiple endocrine neoplasia type 1 syndrome. Clin Cases Miner Bone Metab. 2017;14(2):12330.

186 Marciello F, Di Somma C, Del Prete M, Marotta V, Ramundo V, Carratù A, et al. Combined biological therapy with lanreotide autogel and cabergoline in the treatment of MEN-1-related insulinomas. Endocrine. 2014;46(3):678-81.

187 Ramundo V, Del Prete M, Marotta V, Marciello F, Camera L, Napolitano V; Multidisciplinary Group for Neuroendocrine $\mathrm{Tu}$ mors of $\mathrm{N}$, et al. Impact of long-acting octreotide in patients with early-stage MEN1-related duodeno-pancreatic neuroendocrine tumours. Clin Endocrinol. 2014; 80(6):850-5.

188 Faggiano A, Modica R, Lo Calzo F, Camera L, Napolitano V, Altieri B, et al. Lanreotide therapy vs active surveillance in MEN1-related pancreatic neuroendocrine tumors $<2$ cm. J Clin Endocrinol Metab. 2020 Jan 1; 105(1):dgz007.

189 Frost M, Lines KE, Thakker RV. Current and emerging therapies for PNETs in patients with or without MEN1. Nat Rev Endocrinol. 2018;14(4):216-27.
190 de Herder WW, Niederle B, Scoazec JY, Pauwels S, Kloppel G, Falconi M; European Neuroendocrine Tumor S, et al. Well-differentiated pancreatic tumor/carcinoma: insulinoma. Neuroendocrinology. 2006;84(3): 183-8.

191 Oberg K, Kvols L, Caplin M, Delle Fave G, de Herder W, Rindi G, et al. Consensus report on the use of somatostatin analogs for the management of neuroendocrine tumors of the gastroenteropancreatic system. Ann Oncol. 2004;15(6):966-73.

192 Kulke MH, Bergsland EK, Yao JC. Glycemic control in patients with insulinoma treated with everolimus. N Engl J Med. 2009;360(2): 195-7.

193 Novruzov F, Mehmetbeyli L, Aliyev JA, Abbasov B, Mehdi E. Metastatic insulinoma controlled by targeted radionuclide therapy with 177Lu-DOTATATE in a patient with solitary kidney and MEN-1 syndrome. Clin Nucl Med. 2019;44(6):e415-7.

194 Naik C, Basu S. Peptide receptor radionuclide therapy with (177)Lu-DOTATATE for metastatic neuroendocrine tumor occurring in association with multiple endocrine neoplasia type 1 and Cushing's syndrome. World J Nucl Med. 2017;16:126-32.

195 Grozinsky-Glasberg S, Lines KE, Avniel-Polak S, Bountra C, Thakker RV. Preclinical drug studies in MEN1-related neuroendocrine neoplasms (MEN1-NENs). Endocr Relat Cancer. 2020 Sep;27(9):R345-5.

196 Garcia-Carbonero R, Sorbye H, Baudin E, Raymond E, Wiedenmann B, Niederle B; Vienna Consensus Conference p, et al. ENETS Consensus Guidelines for high-grade gastroenteropancreatic neuroendocrine tumors and neuroendocrine carcinomas. Neuroendocrinology. 2016;103(2):186-94.
197 Daglar HK, Kirbas A, Biberoglu E, Laleli B, Danisman N. Management of a multiple endocrine neoplasia type 1 during pregnancy: a case report and review of the literature. J Exp Ther Oncol. 2016;11(3):217-20.

198 Mistry M, Gupta M, Kaler M. Pregnancy in multiple endocrine neoplasia type 1 equals multiple complications. Obstet Med. 2014; $7(3): 123-5$.

199 Stewart CA, Termanini B, Sutliff VE, Corleto VD, Weber HC, Gibril F, et al. Management of the Zollinger-Ellison syndrome in pregnancy. Am J Obstet Gynecol. 1997; 176(1 Pt 1):224-33.

200 Gulati Anthony P., Krantz Benjamin, Moss Rebecca A., Moyal Wendy N., Tsushima Dawn A., Mowatt Kelley B., et al. Treatment of Multiple Endocrine Neoplasia 1/2 Tumors: Case Report and Review of the Literature. Oncology. 2013;84(3):127-34.

201 Zandee Wouter T, Brabander Tessa, Blažević Anela, Kam Boen L R, Teunissen Jaap J M, Feelders Richard A, et al. Symptomatic and Radiological Response to $177 \mathrm{Lu}-\mathrm{DOT}$ ATATE for the Treatment of Functioning Pancreatic Neuroendocrine Tumors. J Clin Endocrinol Metab. 2019;104(4):1336-44. 10.1210/jc.2018-01991. 30566620.

202 Gezer Emre, Çetinarslan Berrin, Cantürk Zeynep, Tarkun İilhan, Sözen Mehmet, Selek Alev. Metastatic MEN1 Syndrome Treated with Lutetium-177 - A Case Report. Eur Endocrinol. 2019;15(2):92-4. 10.17925/ EE.2019.15.2.92.31616499. 